\title{
LA «ACN DE JP» Y SUS PRIMERAS CAMPAÑAS DE MÍTINES SOCIALES (1909-1910)
}

\author{
POR \\ PABlo SÁNCHEZ GARRIDO ${ }^{1}$ \\ Universidad San Pablo CEU
}

\begin{abstract}
RESUMEN
El objetivo de este artículo es el estudio de los primeros pasos de la ACN de JP durante los años fundacionales de 1909 y 1910. El artículo se centra en las grandes campañas de mítines públicos, desde las primeras de 1909 a la mayores de 1910 . El texto también subraya la relación entre la ACN de JP y la Junta de Vizcaya, así como la decisiva relación con el nuncio español, Mons. Vico. La repercusión de estos actos públicos hizo posible que la ACN de JP emergiera pocos años después como líder del movimiento social y político católico y como germen de la futura democracia cristiana española.
\end{abstract}

PALABRAS CLAVE: Movimientos sociales; ACN de JP; anticlericalismo; mítines sociales; Catolicismo social.

\section{THE «ACN DE JP» AND ITS FIRST CAMPAIGNS OF SOCIAL MEETINGS (1909-1910)}

\begin{abstract}
The aim of this essay is to study the first steps of the historical «Asociación Católico-Nacional de Jóvenes Propagandistas» (later, "ACN de JP») between the foundational years of 1909 and 1910. So the article focuses on the great public meetings developed during its first campaign of 1909 and the greater one developed in 1910. The article also emphasize the relation between ACN de JP and the "Junta de Vizcaya" and the important relationship with the Spanish nuncio, Mons. Vico. The repercussion of this public acts made possible that ACN de JP emerged some years after as the leader of social and political catholic movement and as germen of Christian Democracy in Spain.
\end{abstract}

KEY WORDS: Social movements; Social Catholicism; ACN de JP; Anticlericalism; Social meetings.

COMO CITAR ESTE ARTículo / CITATION: Sánchez Garrido, P. 2017. "La "ACN de JP" y sus primeras campañas de mítines sociales (1909-1910)». Hispania Sacra 69, 140: 689-707. doi: 10.3989/hs.2017.043

\author{
Recibido/Received 31-07-2015 \\ Aceptado/Accepted $\quad$ 04-08-2015
}

En un trabajo previo, del que este artículo es continuación temática y cronológica, se ha analizado la etapa gestacional de la Asociación Católico-Nacional de Jóvenes Propagandistas (ACN de JP) desde sus pasos previos en la congregación de los Luises. ${ }^{2}$ Como se decía en dicho artículo, la fundación de la ACN de JP tuvo dos hitos iniciales: el acto o reunión constitutiva (15.XI.1908) y el acto litúrgico inaugural (3.XII.1909). ${ }^{3}$ Las identidades y semblanzas de los miembros del grupo fundacional de la ACN de JP, cuyo

1 psanchez.ihum@ceu.es / ORCID iD: http://orcid.org/00000002-8720-9602

2 Sánchez Garrido 2016.

3 Se ha empleado la expresión «acto inaugural» puesto que la habitual expresión de "acto fundacional» cierra, a nuestro juicio, erróneamente la posibilidad de considerar la reunión de 1908 como el primer hito fundacional. nombre completo era desconocido en la mayor parte de los casos, se dieron a conocer en dicho artículo previo.

El grupo fundacional estuvo constituido por 18 miembros, todos ellos procedentes de la congregación mariana de los Luises. Pero en su primer acto formal, correspondiente a la reunión constitutiva del 15 de noviembre de 1908 en el colegio de Areneros, hubo un grupo previo de ocho jóvenes congregantes seleccionados y convocados por carta por el P. Ayala. Estos, apodados dentro de la propia historia asociativa como "los ocho de la fama», fueron: Luis de Aristizábal y Machón, Jaime Chicharro y Sánchez-Guío, José Fernández de Henestrosa y Escobedo, Manuel GómezRoldán y de Velo y Arce, Ángel Herrera Oria, José María Lamamié de Clairac y de la Colina, José Palanco Romero y Gerardo Requejo Velarde. A lo largo de 1909, el jesuita fue seleccionando a otros congregantes de los Luises de entre 
los que habían colaborado en sus principales actividades: las veladas públicas y el semanario Hojas sueltas. Así hizo hasta conformar el grupo de los 18 primeros «jóvenes propagandistas», cuya incorporación quedó plenamente formalizada tras el acto litúrgico inaugural de imposición de insignias de la ACN de JP por parte del nuncio Vico, el 3 de diciembre de 1909, en la iglesia de la Inmaculada y san Pedro Claver, que igualmente se inauguraba ese día. Estos otros «jóvenes propagandistas» que se unieron a los ocho previos el 3 de diciembre de 1909, fueron: José Manuel de Aristizábal y Machón -hermano menor de Luis-, Manuel de Bofarull y Romañá, Luis Castel y González de Amezúa, Santiago Cavengt Gutiérrez, Andrés de Montalvo y GómezHermosa, Ventura Prieto -al que no se pudo identificar-, Rafael Rotllán Molina, Mateo de la Villa y Sanz. Aunque José María Sauras Navarro y Juan Colomer Beneito no pudieron asistir a este acto litúrgico, también fueron miembros fundacionales de la ACN de JP. ${ }^{4}$

Este artículo, como el anterior, se nutre de fragmentos de las Memorias inconclusas de Ángel Herrera Oria que permanecían perdidos y es fruto igualmente de una exhaustiva investigación archivística, sin olvidar las irremplazables fuentes orales y documentales aportadas por los respectivos descendientes. Toda esta búsqueda archivística previa ha sido combinada con una amplia investigación hemerográfica. Sobre esta base del rastreo de la identidad y actividades iniciales del grupo previas a la fundación de la ACN de JP, en el presente artículo se analizan las actividades inmediatamente posteriores al momento fundacional, fundamentalmente los mítines católico-sociales desarrollados durante los años iniciales de 1909 y 1910. ${ }^{5}$ Dichos mítines tuvieron una repercusión crucial en consolidación interna de la ACN de JP como movimiento católico pero también en la propia historia política de la España del momento. Con este análisis de los mítines se cierra la exhaustiva revisión de los años fundacionales de esta importante asociación a la cual se refería José Andrés-Gallego como «[...] una de las sociedades más importantes de la España contemporánea». ${ }^{6}$

\section{EL MOMENTO CONSTITUTIVO DE LA «ACN»: LAS CAMPAÑAS PIO-} NERAS Y LOS MÍTINES PREINAUGURALES DE 1909

El comienzo del siglo xx alboreaba en España bajo signos de anticlericalismo en varios órdenes, desde el ámbito cultural, con el sonado estreno de Electra de Galdós; hasta el social y periodístico, con las polémicas por el caso Ubao; sin olvidar el ámbito político, con el llamado «Gabinete Electra» de Sagasta y varios intentos de controlar estatalmente la proliferación de órdenes religiosas -como el «proyecto Dávila» de Asociaciones, precedente de la "Ley del Candado" ${ }^{7}-$, así como leyes a favor de la educación laica

\footnotetext{
4 Para las semblanzas de estos miembros, véase el artículo previo a este: Sánchez Garrido 2016.

5 Téngase en cuenta que los años 1909 y 1910 están huérfanos documentalmente puesto que el Archivo Histórico de la Asociación de Propagandistas se quemó en 1936, El Debate comenzó su andadura con la ACN de JP en noviembre de 1911 y el Boletín interno de la ACN de P es bastante posterior.

6 Andrés-Gallego 1993: 252-253.

7 Este decreto ya provocó en 1906 diversas manifestaciones católicas, como las de Pamplona y Barcelona.
}

o del matrimonio civil -como el "decreto Romamones»-, etc. Todo ello a su vez potenció considerablemente la enquistada reacción tradicionalista e integrista. Así las cosas, la «cuestión religiosa» se prometía candente al iniciarse el siglo. Sin embargo, el primero de los periodos cronológicos que ahora nos ocupa -finales de 1908 y primera mitad de 1909-, fue algo más tranquilo en este sentido ya que el llamado "gobierno largo» de Maura mantuvo una política favorable hacia la Iglesia que hasta el propio papa Pío X parece que miró con simpatía. Esto realimentó en ciertos sectores la posibilidad de que el movimiento católico pudiera apoyar la vía conservadora dinástica, más próxima ideológicamente a cierto liberalismo de tipo conservador. Asimismo, frente a los sectores católicos integristas que rechazaban las medias tintas conservadoras y llamaban a una confrontación con el sistema liberal, las sucesivas normas pontificias, como la Cum multa (1882), la Inter catholicos Hispaniae (1906), o las "Normas a los católicos españoles» (como las de abril de $1911)^{8}$, desautorizaron el maximalismo integrista y propiciaron otras vías más moderadas y menos confrontativas, convergentes con la «teoría del mal menor». Ya León XIII había puesto las bases del accidentalismo, doctrina que años después sería consigna de Herrera en la dirección de El Debate y de los propagandistas. No obstante, una parte muy considerable del movimiento católico español y diversos elementos de la Jerarquía pensaban que la vía que representaba el conservadurismo, o bien era cuestionable en su aproximación al liberalismo anticlerical, o bien estaba desgastada en el intento continuamente fallido de aglutinar a las masas católicas. ${ }^{9}$ De este último parecer era el nuncio Antonio Vico quien ansiaba el desarrollo de un bloque católico alternativo que desde otras opciones católicas suprapartidistas lograran coaligar a la mayor parte del espectro ideológico católico, esquivando tanto la Escila integrista como la Caribdis liberal. ${ }^{10}$ Esto fue lo que seguramente vislumbró en la naciente ACN de JP, que de hecho él mismo había contribuido a fundar y a la que apoyó de un modo tan decidido para un nuncio. Esta meta se unía al paralelo llamamiento pontificio, ejecutado también por Vico, de promover la reorganización efectiva de la Acción Católica en España siguiendo el modelo italiano. Para ello, en 1908 el nuncio Vico envió a los obispos españoles por indicación de la Santa Sede una encuesta y unas bases o normas para la unión de los católicos en los tres frentes fundamentales: social, propagandístico y político-electoral. ${ }^{11}$ Precisamente para este objetivo de (re) organizar la Acción Católica en España llamó el nuncio al P. Ayala y ese fue el germen de la ACN de JP. ${ }^{12}$

8 A lo que hay que añadir las «Normas de acción católica y social» del primado Aguirre (1910, completadas en 1912) -dictadas a instancias del papa-, y las Normas dadas en Roma a los integristas españoles (1908).

9 Cfr. Robles 1991a: 189.

10 Según le expuso Vico a García Ocaña sobre la ACN de JP: «Ellos no eran ni carlistas ni anticarlistas, ni integristas ni anti-integristas, ni amigos ni adversarios de ningún partido político, sino defensores de la religión, y su periódico El Debate era el mejor órgano de esa unión de los católicos», Carta de J. M.a García Ocaña, desde ICAI, a I. Zameza, 10.XII.1911, ARSI (Roma), Tolet 1003-VII. Leg. 5.

11 Para la participación de Vico en las encuestas pontificias para que la Acción Católica española siguiera el modelo italiano, véase: Montero, 1992.

12 Cervera 2009 [primera edición 1975]. Ángel Ayala: 132. Madrid: CEU Eds. 
Pero la relativa tranquilidad político-religiosa del periodo maurista iba a cambiar bruscamente a partir del verano de 1909, con los acontecimientos derivados del estallido de la Semana Trágica. Los sucesos fueron promovidos por sectores sindicalistas y anarquistas y detrás andaba un joven y radical Lerroux -que curiosamente décadas más tarde acabaría aliándose con la CEDA y que al final de su vida sería amigo personal del Obispo Ángel Herrera Oria-. ${ }^{13}$ Unas protestas inicialmente antibelicistas por el llamamiento a filas para el conflicto de Marruecos acabaron por convertirse en una violenta insurrección de deriva anticlerical, con quema de conventos, iglesias y colegios religiosos y una tardía pero durísima represión por parte del gobierno de Maura y con la polémica ejecución del supuesto cabecilla. El recrudecimiento del ambiente antimaurista -con el famoso «iMaura no!»- llevaron al rey a aceptar su dimisión, tras lo cual se encadenaron tres gobiernos liberales que fueron considerados especialmente anticlericales y laicistas por parte de los sectores católicos: uno breve y débil de Segismundo Moret, el del de Canalejas y el del Conde Romanones -tras un gobierno «en funciones» de dos días del Marqués de Alhucemas posterior al asesinato de Canalejas-. En el anticlericalismo de estos gobiernos liberales había, sin embargo, una parte o mucho de concesión a las pujantes izquierdas. Principalmente durante el gobierno de Canalejas, que además se consideraba católico, se abrió una época especialmente conflictiva respecto a la "cuestión religiosa», puesto que con el contexto previo de la Semana Trágica -en el plano del anticlericalismo popular-, el gobierno propuso una serie de medidas anticlericales, como: la «Ley del Candado ${ }^{14}$, la retirada de embajador en el Vaticano, la propuesta del Real Decreto de reapertura de las «escuelas laicas», el permiso de símbolos públicos a confesiones no católicas, o la retirada de la exención del servicio militar a los religiosos. De hecho el ataque a las políticas anticlericales durante el gobierno de Canalejas fue uno de los principales objetivos del movimiento social católico del momento. ${ }^{15}$ Tanto la Jerarquía de la Iglesia y el nuncio como el movimiento católico seglar interpretaron estas y otras medidas similares como un desafío o afrenta y se iniciaron diversas reacciones y movimientos de protesta. El ambiente político general estaba ya de por sí muy tensionado de lo cual nos dan muestra hechos que fueron desde la amenaza de

13 En diversos lugares se narra la anécdota de que en una visita que el obispo Herrera le hizo a Lerroux, el antiguo político radical, le hizo la promesa de rezar tres avemarías cada día y manifestó que cumplió su promesa. Para un estudio sobre la Semana Trágica desde esta perspectiva, véase: Andrés-Gallego 2009.

${ }^{14}$ La Ley del Candado de 1910 tenía un único artículo que decía: «No se establecerán nuevas Asociaciones pertenecientes a Órdenes o Congregaciones religiosas canónicamente reconocidas, sin la autorización del Ministerio de Gracia y Justicia [...] mientras no se regule definitivamente la condición jurídica de las mismas». Nunca llegó a entrar en vigor por una enmienda hábilmente propuesta por el Marqués de Comillas que establecía un plazo máximo de ejecución de dos años so pena de quedar sin efecto la ley, como así ocurrió. La oposición fue fortísima pues argumentaban los católicos, como Vazquez de Mella, que no solo era un "atentado» anticlerical sino que además iba contra el derecho de asociación e incluso era contradictoria respecto al propio Estado liberal. Vázquez de Mella. Para sus precedentes, véase: Cárcel Ortí, 2003.

15 Sobre Canalejas, véase: Sevilla 1956 -con un interesante prólogo de Jesús Pabón-; Zancada, 1911; Francos Rodríguez 1918 y Sánchez Arjona 1947. atentado personal proferida por Pablo Iglesias contra Maura si volvía al poder, hasta el asesinato del entonces presidente Canalejas en 1912 por parte del anarquista Pardiñas.

En todo este contexto agitado y anticlerical, la recién creada ACN de JP fue la que pasó a liderar la mayor parte de los movimientos sociales de protesta durante el crucial año 1910 en alianza con el movimiento de las Juntas católicas liderado por José M. a Urquijo. La gran cuestión subsiguiente era qué grupo lograría en las décadas posteriores levantar y liderar el «movimiento católico», así como su posible canalización política o electoral. Frente a la vía tradicionalista/integrista y la conservadora/dinástica, la ACN de JP quiso representar la opción de lo que se llamó "católicos independientes», opción desde la que se intentó la difícil, si no imposible, tarea de intentar aglutinar y coordinar a las otras dos. El riesgo de que acabaran descalificados como «mestizos» por los unos, e integristas por los otros, no era pequeño. La cuestión de cómo logró evolucionar casi desde la nada una asociación de jóvenes que años más tarde logró ofrecer esta tercera opción e influir decisivamente en la historia española puede encontrar algunas vías de respuesta en este artículo.

Si nos centramos en el propio decurso inicial de la ACN de JP, hubo, como ya se ha dicho, dos hitos iniciales, el de 1908 y el de 1909. Pero, ¿qué pasó entre esas dos fechas, entre la reunión constitutiva del 15 de noviembre de 1908 y el acto inaugural del 3 de diciembre de 1909? Una vez que el padre Ayala convocó la reunión de noviembre de 1908 parece que la ACN de JP quedó constituida a diversos efectos, sobre todo el de su primera actividad: dar mítines de propaganda católica por toda España. Las últimas semanas de 1908 y los primeros dos meses de 1909 se dedicaron a la planificación de las primeras campañas de mítines, especialmente para los tres primeros mítines post-constitutivos de Ciudad Real, Badajoz y Toledo, celebrados entre marzo y junio de 1909. Se reunían para su organización todos los viernes, actuando Herrera como presidente y Requejo como secretario ${ }^{16}$; mientras que reservaron los primeros domingos de cada mes para ensayar discursos o mítines a partir de un reparto previo de los temas de especialización-Herrera por ejemplo, escogió los temas de Derecho Político- ${ }^{17}$ Tomaban como público de ensayo a los alumnos del Centro Social de ICAI. ${ }^{18}$ Otra actividad que se desarrolló ya durante este interludio fue la preparación de las "bases de un rotativo católico» y de las gestiones que concluirían en la adquisición de El Debate; bases que los «jóvenes propagandistas» y el P. Ayala hicieron llegar a la Santa Sede entre finales de 1908 y marzo de 1909. De hecho el P. Ayala había iniciado las gestiones económicas y eclesiásticas para la adquisición del rotativo católico antes de la reunión constitutiva de 1908, como se prueba más adelante. De los ensayos previos de propaganda oral y escrita en los Luises que se materializaron respectivamente en las veladas literarias y en las Hojas Sueltas -que se analizaron en el artículo previo a este-, los jóvenes propagandistas iban a pasar a los «mítines monstruo» y al lanzamiento del gran rotativo católico nacional.

16 Cfr. Boletín de la ACNP (en adelante, BACNP) 1.I.1955 p. 2.

17 BACNP no 95, 1930. Téngase en cuenta que Herrera iba a opositar a cátedra para esta materia y que la disciplina encontraba muchos temas de conexión con la Doctrina Social de la Iglesia y con lo que entonces se conocía como «Derecho Público Cristiano».

18 Cfr. Revuelta 1991, Vol. II, p. 579 y 968-969. 
La primera campaña tuvo dos mítines - no tres, como se recoge en casi todas las fuentes previas-, comenzando con un mitin en Ciudad Real, seguido de otro, pocos días después, en Badajoz. Pero el mitin de Toledo no formó parte de esta "primera salida» pues de hecho se celebró casi tres meses después. ${ }^{19}$ Por el carácter programático de esta primera terna de mítines de la ACN de JP y por ser prácticamente desconocidos en su contenido a efectos historiográficos, voy a dedicarles una mayor atención. ${ }^{20}$

Lo más significativo del primer mitin en Ciudad Real, es que fue el pistoletazo de salida para el tipo de propaganda católica que iba a marcar el primer periodo de esta Asociación. Así, varios de estos jóvenes iniciaron su "primera salida» para dar «mítines católicos», con el objetivo transmitido por el P. Ayala de despertar la adormecida conciencia católica de la sociedad religiosa española. Según definió el diario El Salmantino a la naciente ACN de JP: «El fin de esta Asociación [...] es llevar a la plaza pública y a la calle, en mítines y conferencias, las doctrinas y soluciones católicas y oponerlas a los socialistas y liberales, y singularmente enaltecer la acción social católica». ${ }^{21}$ Una salida que tenía mucho de quijotesca, tanto en el destino geográfico manchego como en la actitud, ya que, como recordaba Herrera en 1935: "Salimos de propaganda la primera vez Requejo, Clairac y yo, como verdaderos quijotes, sin saber a qué». ${ }^{22}$

Era este mitin el paso crucial desde las veladas con público afín y «jugando en casa», al estreno público en plazas y teatros de ciudades extrañas a ellos y con público incierto, pues como afirma Lamamié de Clairac en el segundo mitin: «Acostumbrado yo a presentarme en público tan solo allá en las academias de mi colegio, y posteriormente en las veladas de nuestro Círculo en Madrid, que al fin y al cabo vienen a ser como presentarse en familia, me encuentro ahora en este gran teatro, ocupado por personas de todas las clases sociales $[\ldots] »{ }^{23}$

El primero de estos mítines fue en la noche del 25 de marzo de 1909 en Ciudad Real, ciudad natal del P. Ayala, donde la familia del jesuita tenía notable arraigo, factor que

19 Por entonces los mítines eran más bien políticos y de los progresistas por lo que este tipo de mítines sociales y católicos eran una rareza, cuando no fueron interpretados como una provocación. Lo explican Isidoro Martín y González Ruiz: «Estaba de moda la reunión pública designada por el consagrado anglicismo "mitin". Los congregados de Areneros acordaron asociarse para dar mítines. Mítines de propaganda». «¿De cuál?», se preguntaba el padre Ayala. Y él mismo responde: "De cualquiera con tal que fuese católica», Martín y González Ruiz 1968: 33. Según lo expresa Herrera en sus memorias: «No se celebraban mítines [católicos]. La palabra mitin parecía estar reservada a las izquierdas anticlericales. Si había algún acto de protesta rara vez salía de los salones de actos de los centros o congregaciones religiosas. Pero el teatro, el frontón y a veces la plaza pública estaban reservados a las izquierdas", Memorias del Cardenal Herrera, leg. A, Archivo del Cardenal Herrera, Fundación Pablo VI, p. 1.

20 Del primer mitin de Ciudad Real puede encontrarse una descripción en Gutiérrez 2010: 21, pero señala que del segundo y tercero, en Badajoz y Toledo, no pudo encontrar la crónica periodística de los mismos en la prensa de la época -incluso consultando al cronista oficial de la ciudad-; crónicas que se han podido recuperar para este artículo.

21 El Salmantino, 19.XII.1909, p. 3.

22 BACNP, n. 203-204, 1935, p. 6.

23 ESF, 3.IV.1909, p. 1; también El Salmantino, marzo de 1909, p. 2, donde reproduce la noticia de El noticiero extremeño. seguramente determinó la celebración allí del mismo. ${ }^{24} \mathrm{El}$ acto contó con una destacada presidencia, compuesta por el Obispo Remigio Gandásegui y el Alcalde, y se celebró en el Círculo Católico Obrero de la Sagrada Familia, obteniendo, según la crónica, un enorme éxito entre la concurrida asistencia. En su intervención, tras aludir Herrera a la creación de la nueva asociación a la que representaba, habló de la defensa de los obreros y de "la necesidad de que los católicos tomen parte en el movimiento social»; Lamamié de Clairac habló de los sindicatos católicos, defendiendo la idoneidad de los «sindicatos profesionales puros» frente a los "sindicatos mixtos» de patronos y trabajadores y abogando por la necesidad de sindicalistas liberados; mientras que Gerardo Requejo habló del «Evangelio y la cuestión social». ${ }^{25}$ Según indica la crónica, este último fue «elocuentísimo, logrando arrebatar de entusiasmo al auditorio» y siendo interrumpido por los aplausos repetidamente. Parece que en este primer mitin, Requejo logró incluso brillar más que el joven Herrera, pues abrió con una lírica apelación, en la propia tierra manchega, al Quijote como ideal espiritual frente a la mentira y a la injusticia, y realizó un exordio de León XIII, «el padre de los trabajadores y el propagador de la doctrina social católica, floración de los Evangelios». Aludió a Cristo como "obrero del taller de Nazaret» que fue crítico frente a los ricos y recreó épicamente las palabras del juicio final: "Tuve hambre y me disteis de comer...», para concluir apelando a la necesidad de un amor auténtico entre las clases sociales. $^{26}$

El segundo mitin fue un lluvioso domingo en el Teatro López de Ayala de Badajoz, concretamente el 28 de marzo de 1909 -no el 30, como han indicado diversas fuentes-. ${ }^{27}$ Participaron los mismos ponentes que en el de Ciudad Real, pero la mesa estaba presidida en este caso por el obrero Juan Díez. Recordaba Herrera casi cincuenta años después: «El acto de Badajoz causó en mí una profundísima impresión, porque aunque se inició con un aparente fracaso se puede decir que fue el primer éxito con que Dios nuestro Señor nos alentó a aquella empresa generosa [...]. Fue glacial el recibimiento que nos hizo el público, no muy numeroso, que había en el teatro, pero nuestro entusiasmo juvenil logró enardecerlo y moralmente se caldeó la sala y se levantaron los espíritus, y como consecuencia salimos muy animosos y confortados

24 Quizá ello explique igualmente el apoyo institucional que recibió el acto. La composición de los miembros de la mesa da cuenta de este apoyo recibido pues además del Obispo prior de las órdenes militares, estaban en la mesa: el Alcalde, el Teniente Alcalde, el Presidente de la Diputación, un magistrado de la Audiencia provincial, el Presidente de Acción Social en la capital, el Marqués de Casa Treviño, y «el reverendo P. Herrera». El Siglo Futuro (en adelante, ESF), 2.IV.1909, p. 1. También está referido el mitin en Diario de la Mancha, 26.III.1909, pp. 1-2.

25 ESF, 2.IV.1909, p. 1.

26 Ídem.

27 Recojo la crónica de ESF, 3.IV.1909, p. 1 y de El Salmantino, marzo de 1909, p. 2, que a su vez lo recogen de Noticiero Extremeño. Para una crónica satírica del acto hecha desde un periódico republicano, véase: $L a$ Región Extremeña, 31.III.1909, pp. 1 y 2. Para las referencias al mitin del P. Ayala, véase el Boletín de la ACN de P (en adelante, BACNP) 1.I.1955 p. 2. Tanto en esta última como en la carta de Herrera posteriormente, se dice que el mitin fue el 30 de marzo -desde donde el error se extiende a diversas publicaciones históricas-, pero el cotejo que aportan esas diversas crónicas periodísticas de la época, que contaron con cronistas oculares diversos, nos confirman que por el contrario tuvo lugar el domingo 28. 
de esta primera aventura quijotesca». ${ }^{28}$ La crónica del acto indica que la primera intervención correspondió al obrero Juan Díez, que propuso a la Iglesia como defensora de la auténtica libertad y exhortó a los obreros a no apartarse de la fe. Le siguió en la palabra Lamamié de Clairac, que volvió a defender a los sindicatos como medio para la «dignificación y mejoramiento del proletariado", labor en la que debían colaborar todas las clases sociales. Tras reivindicar una organización sindical corporativa con raíces en las cofradías y gremios medievales, expuso la necesidad de su implantación siguiendo la doctrina social de León XIII y Pío X. Acabó con un alegato contra la destrucción liberal de las formas corporativas y municipales de organización social, intervención en la que el joven Lamamié dejaba ver ya su filiación tradicionalista que después manifestó como diputado y que le llevó a separarse poco después de la ACN de JP. ${ }^{29}$ Herrera inició su intervención con un golpe de efecto retórico, confesando que renunciaba al discurso que tenía preparado a causa del entusiasmo provocado por las palabras previas de ese obrero «que con su chaqueta de trabajador nos avergüenza con el ejemplo de su fe a nosotros los que vestimos de levita». Con lo que parece que acabó ganándose al público fue con la recreación del pasaje bíblico en el que el profeta Ezequiel aparece entre un campo de huesos y esqueletos y tras cumplir el profeta la orden divina de predicar sobre esos huesos estos comenzaron a erigirse y a revestirse de carne y, ya dotados de espíritu, acaban convertidos en un ejército temible. Después de la dramática recreación, Herrera estableció un paralelismo entre este pasaje y la situación del catolicismo español: «iCuántos huesos secos y áridos hay en España, que sólo esperan que descienda sobre ellos la palabra del Profeta» y acabó reivindicando la necesidad de que el catolicismo español se lanzara «a la conquista del restablecimiento de nuestra gloriosa tradición». La crónica describe una gran ovación final. Parece que el entrenamiento del jesuita surtía su efecto. El colofón correspondió nuevamente al "fogoso» Gerardo Requejo, al que el diario le dedica el doble de espacio. Comenzó reconociendo su amor a la tierra y espíritu extremeños y glosando a sus grandes conquistadores como Hernán Cortes, Pizarrro, o las poesías de Gabriel y Galán; a continuación expuso el tema de su intervención: "cómo la prensa católica es la única prensa defensora de los intereses de los trabajadores». Criticó con energía a la prensa socialista y anticlerical por estar «[...] vendida al trust ${ }^{30}$ de los poderosos

28 Carta de Herrera a Herminio Pinilla, director de Hoy, de Badajoz, 2.I.1958. Archivo del Cardenal Herrera Oria. Fundación Pablo VI.

29 El Salmantino, marzo de 1909, p. 2. Incluye Lamamié una crítica a la ley de régimen local que por entonces se discutía en el Senado.

30 «El trust» era el nombre popular con el que se conocía a la «Sociedad Editorial de España», un consorcio periodístico empresarial dirigido en 1906 por Miguel Moya y apoyado por Canalejas para unir a los más influyentes periódicos progresistas del momento, como Heraldo de Madrid, El Liberal, o El Imparcial. El enfrentamiento entre la prensa católica -autodenominada «Buena Prensa»-y los diarios del trust, a los que se acusaba de ser un órgano de la masonería o de un anticlericalismo radical, fue una constante desde su aparición. Aunque contó con una importante ayuda financiera -incluso de fuentes conservadoras, como la del político Juan de la Cierva-, el trust entra en quiebra en 1922, transformándose un año después en la Sociedad Editora Universal. No obstante, tuvo tiempo de convivir con su antagonista católico creado por la ACN de JP: EDICA. Cfr. Cruz Seoane y Dolores Sáiz 1996. Es especialmente detallado sobre el trust el análisis de Gómez Aparicio 1974: 241-277. que en pasados conflictos se colocó al lado de las grandes industrias [...]", acusando a los diarios El Imparcial, El Liberal y Heraldo de Madrid "porque son explotadores del obrero». Finalmente, hizo una encendida defensa de la prensa católica que también recibió un caluroso aplauso, según el diario. ${ }^{31}$

Según narra Herrera en sus memorias: «El resultado de esta primera experiencia fue confirmarse el Padre en sus propósitos y así, antes de terminar el curso nos anunció que haríamos la primera gran campaña en Andalucía, en el mes de diciembre del mismo año de 1908 [sic]». ${ }^{32}$ Posiblemente, a partir de aquí comenzaron las reuniones con el Nuncio y las cartas preparatorias para organizar la primera gran campaña de mítines de Andalucía de diciembre de 1909, que comenzó por Granada.

El tercer mitin de la ACN de JP fue el 15 de junio de 1909 en Toledo, pero por un error sobre la narración conjunta de estos tres mítines pioneros, que décadas después haría el P. Ángel Ayala, se ha reproducido en diversos lugares que fueron protagonizados por los mismos propagandistas (Herrera, Lamamié y Requejo) y que estuvieron conectados en fechas consecutivas dentro de la primera salida. ${ }^{33}$ Pero la tercera crónica hallada demuestra que en realidad el único orador que repitió en el mitin de Toledo fue Requejo y que entre los dos primeros mítines y el tercero mediaron más de dos meses. ${ }^{34}$ Se trató por tanto de una segunda salida, separada en fecha y protagonistas. Los demás ponentes de este tercer mitin, fueron: Luis de Aristizábal, Andrés de Montalvo, José Palanco y Manuel Gómez-Roldán. Otro de los jóvenes propagandistas, Manuel de Bofarull, asistió a la mesa de prensa en el escenario, pero en calidad de representante del periódico El Correo Español, sin participar como orador. Con esta segunda salida, siete de los ocho primeros propagandistas ya habían salido a la escena pública. El cronista del periódico carlista El Porvenir señala que el teatro estaba lleno hasta los palcos, con escasas butacas vacías, y enfatizaba en su crónica la condición antiliberal de los propagandistas. ${ }^{35}$ El encargado de abrir el mitin fue Luis de Aristizábal, que presentó el programa de la ACN de JP glosando tres palabras clave: Religión, Sociedad, Política; e hizo una defensa del Instituto de Reformas Sociales frente al socialismo. ${ }^{36}$ Montalvo dedicó

31 Aunque coincidió que el P. Ayala estaba en Badajoz adonde había ido «al cumplimiento pascual de los campesinos de una finca de sus padres", no asistió al mitin, ni a ninguno de los posteriores de la ACN de JP. BACNP 1.I.1955 p. 2.

32 Memorias... A, p. 3.

33 La narración de Ayala 1999: 295. Sobre el error en la composición y fecha del tercer mitin, Seglares... p. 34 y BACNP 1.I.1955 p. 2; y de aquí pasa a otros autores que recogen estas narraciones.

${ }^{34}$ No es posible que hubiera otro entre medias porque los dos medios locales que reproducen el acto así lo hubieran indicado, como hicieron cuando volvieron a Toledo dos jóvenes propagandistas en el mes de noviembre. En dicha ocasión, el diario señala que ya conocían a Palanco por la anterior ocasión en el Teatro Rojas, mientras que no dice nada de Herrera, que fue el otro ponente. El acto fue recogido en el diario carlista El Porvenir, 16.VI.1909, p.1.

35 El antiliberalismo era un rasgo común a casi todo el catolicismo social español de la época y no específico del integrismo o del carlismo, como se indica más adelante.

36 Sobre la participación católica en la gestión del IRS había habido una polémica a propósito de Eduardo Dato y de las candidaturas católicas para su Junta en marzo de 1908 en ESF y en El Correo Español. José M.a Urquijo logró que salieran las candidaturas católicas en el norte de España. cfr. Robles 1997: 218-220 
su discurso a atacar el anticlericalismo y afirmó que «el anticlericalismo en la enseñanza es antidemócrata» al impedir la enseñanza gratuita que la Iglesia proporciona al pueblo. A continuación, tomó la palabra Gerardo Requejo, a quien el cronista de El Castellano calificó como «héroe de la noche». ${ }^{37}$ Dedicó su intervención a defender a las órdenes religiosas, puesto que «no solo predican, también dan trigo", centrándose fundamentalmente en elogiar la contribución de los comedores sociales y las labores de ayuda a los huérfanos y a los enfermos hospitalizados de las Hermanas de la Caridad. Posteriormente, habló José Palanco -el periódico señala "Polanco», errata muy frecuente en la transcripción de su apellido-, que se centró en la cuestión social, defendiendo el derecho de los trabajadores a la huelga, la cual en determinadas condiciones, señala, «es hasta santa». Posteriormente, defendía la igualdad de todos los hombres ante Dios y la conveniencia de que la sociedad se organice en asociaciones, para aludir finalmente a otro tema recurrente en estos mítines: el de "la buena prensa». El último en hablar fue Manuel Gómez-Roldán, al que el P. Ayala, como curioso método de choque para «curarle de espanto» ante sus nervios, le había pedido que cambiara el tema de su intervención justo unos momentos antes de comenzar. ${ }^{38}$ El nervioso conferenciante, aprovechando la concurrencia femenina, habló sobre la función educadora de la mujer y sobre la necesidad de que formen ligas contra la mala prensa y teatro, para referirse finalmente a la dignificación de los obreros.

Otro hecho tampoco recogido en otros estudios históricos que han tratado sobre los orígenes de la ACN de $J P$, es que, durante el mes de noviembre de 1909 y antes de la importante campaña andaluza, estos iniciaron una serie de campañas menores de mítines comenzando el 14 de noviembre de 1909 en el Centro de Acción Social de Alcalá de Henares. Intervinieron en este mitin Rafael Rotllán, exponiendo sobre "La acción social y la acción política»; Jaime Chicharro, que habló sobre «Los liberales y la libertad de pensamiento" y Mateo de la Villa, que disertó sobre "La revolución y los provechos del pueblo». ${ }^{39}$ Además, a propósito de este acto se anuncia que es el «primero de una serie que piensa dar en Ávila, Chinchón, Toledo, Ciudad Real, Cáceres, Badajoz, Sevilla, Jerez, Cádiz y Granada». ${ }^{40}$ Nótese que se presentan secuencialmente unidos estos mítines menores con la campaña andaluza posterior al momento inaugural de 1909.

De todo lo anterior se deduce que la organización de estos primeros mítines de 1909 no fue por tanto azarosa, ni

37 El Castellano, 19.VI.1909, p. 1. Se firma con el seudónimo «Deo-Dato».

38 Él mismo lo recordaba años después: «Cuando con mucho miedo por mi parte nos dirigíamos al teatro, el Ayala me preguntó: «¿De qué va usted a hablar?». Y cuando le respondí el tema que había preparado, me dijo: «Pues hable usted de esto otro». Me curó de espanto para siempre». BACNP, n. 95 julio (1930), p. 1.

39 El porvenir, 17.XI.1909, pp. 2-3.

40 El Salmantino, 20.XI.1909, p. 1. El mismo diario, cuando un mes después da noticia del acto fundacional del 3 de diciembre, tan solo señala que previamente habían celebrado mítines en Ciudad Real, Badajoz, Toledo, Alcalá de Henares y Ávila, sin incluir Chinchón. Tampoco La Lectura dominical 27.XI.1909, p. 764, habla de ningún otro mitin en Chinchón, por lo que seguramente no se celebró y pasaron directamente a la campaña por Andalucía, después del acto del 3 de diciembre. improvisada, sino que respondió a un plan organizado meticulosamente con antelación, envío de cartas preparatorias, entrenamiento previo, etc.

El siguiente mitin que se ha encontrado de esta segunda serie de 1909 es el segundo que dieron en Toledo, el domingo 21 de noviembre. La particularidad de este segundo mitin toledano es que aparece otro joven propagandista que faltaba dentro de ese grupo de los ocho iniciales, se trata de José Fernández de Henestrosa ${ }^{41}$, que hizo un discurso en cuyo tono se le fue la mano hacia lo demagógico al hablar en contra de la escuela laica. ${ }^{42}$ Los demás oradores fueron: Palanco, cuyo título fue: "La prensa anticatólica explota la credulidad", y Herrera, que tuvo como tema "Los católicos y las elecciones». El 28 de noviembre, Ángel Herrera daba en solitario una conferencia en el Círculo Católico de Obreros de Ávila. ${ }^{43}$

\section{EL MOMENTO INAUGURAL DE DICIEMBRE DE 1909 Y LOS LÍMITES DE LA «GRAN CAMPAÑA ANDALUZA»}

El segundo gran momento fundacional de la Asociación, la que fue su presentación o "puesta de largo» social y eclesial, fue el 3 de diciembre de 1909 -día del jesuita misionero san Francisco Javier-, fecha en la que el nuncio del papa san Pío X, Mons. Vico impuso las primeras insignias asociativas a los jóvenes propagandistas. ${ }^{44}$ Se hizo coincidir el acto con el de la inauguración de la nueva iglesia de la Inmaculada y San Pedro Claver. La ceremonia litúrgica dedicada a los jóvenes propagandistas comenzó a las ocho de la mañana en la nueva iglesia, sita en el número 25 de la madrileña calle de Areneros. ${ }^{45}$ Comenzó con la bendición de las insignias de los «jóvenes propagandistas» por parte del nuncio Vico, quien a continuación les «dio bendición especial del Sumo Pontífice, como armándolos espirituales paladines para las grandes causas de la Iglesia y de la civilización». ${ }^{46} A$ continuación, se celebró una eucaristía oficiada por el Nuncio y solemnizada por el órgano y coro de San Pedro Claver. Igualmente, se leyó la «oración de los propagandistas», compuesta por el P. Ayala. ${ }^{47}$ En cuanto al concurrido público asistente, El Siglo Futuro (en adelante, ESF) detalla: "No sólo los dos centenares de alumnos y el profesorado seglar en masa [se refiere al de ICAI y colegio], sino multitud de fieles de ambos sexos $»{ }^{48}$

41 El Porvenir, 24.XI.1909, p. 1. ESF, 24.XI.1909, p. 1.

42 "[...] verdaderos antros donde incuban los monstruos que escupen al cielo y escarnecen la bandera bendita de la patria o que a título de humanidad producen hecatombes como la de la semana roja y se adiestran en la confección de aparatos con que ametrallan al pueblo irresponsable de las desigualdades sociales», El Porvenir, 24.XI.1909, p. 1.

43 El Lábaro, 29.XI.1909, p. 3; La Correspondencia de España, 29.XI.1909, p. 5.

44 Antonio Vico (1847-1929) fue nuncio de san Pío X entre 1907 y 1912. Previamente había sido secretario del anterior nuncio Angelo di Pietro y de Serafino Cretoni, en cuya función realizó unos interesantes informes sobre la situación del catolicismo español, publicados y analizados por Vicente Cárcel Ortí.

45 El acto de inauguración de la iglesia prosiguió por la tarde. La Época, 3.XII.1909.

46 La Lectura dominical, 11.XII.1909, pág. 12

47 BACNP 1.I.1955 p. 2. Tanto la oblación como la oración primitivas pueden leerse en Gutiérrez 2010: 47 y ss.

48 ESF, 3.XII.1909. p. 2. El Siglo Futuro fue fundado por Cándido Nocedal en 1875. Inicialmente carlista a partir de 1889 deriva hacia el integrismo. De carácter marcadamente antiliberal, protagonizó 
Sin embargo, aunque ha sido frecuente señalar este acto como el momento fundacional de la ACN de JP, lo cierto es que, como se ha visto, antes de ese 3 de diciembre los «jóvenes propagandistas» del grupo fundacional ya se presentan explícitamente en sus mítines católico-sociales como pertenecientes a la «Asociación Católico-Nacional de Jóvenes Propagandistas». Por tanto, siendo rigurosos no podría decirse que la ACN de JP se funda o «nace» el 3 de diciembre de 1909 sino que esta es la fecha en que, si se me permite el símil, se celebra su «bautizo», ya que siguiendo con la imagen para que haya "bautizo" tiene que haberse producido previamente el nacimiento de la criatura. El P. Ayala lo expresa de un modo que también corrobora esta cuestión: «El 3 de diciembre de 1909, monseñor Vico, Nuncio de Su Santidad, impuso la insignia de la Asociación CatólicoNacional de Propagandistas a todos los que en aquella fecha pertenecían a ella». ${ }^{49}$ Según lo explica ESF, con este acto, formalizado en la bendición e imposición de insignias, lo que hizo el Nuncio fue dar "existencia canónica» a la ACN de $\mathrm{JP}^{50}$, pero respecto a una asociación ya existente y operativa, al menos en el nivel fáctico de los mítines católicos. Cabe añadir que en dichos mítines previos al 3 de diciembre los jóvenes propagandistas, además de presentarse ya abiertamente como "ACN de JP», portaban asimismo la insignia asociativa, como se deduce de la presentación que hace de ellos El Porvenir en el mitin toledano de junio de $1909 .{ }^{51}$ A esto se une una narración que hace Herrera de aquella primera reunión de 1908 convocada por el P. Ayala en Areneros: «[...] una tarde del mes de noviembre de 1908, doce o trece congregantes marianos reuníanse en Areneros, citados por el P. Ayala, que les expuso la idea, y quedó fundada nuestra Asociación». ${ }^{52}$

También es llamativo el hecho de que diversas fuentes de la época se refieren a la ACN de JP no solo como una asociación nacida de las congregaciones marianas sino que hablan de ella como "una nueva congregación mariana». ${ }^{53}$ Así ocurre por ejemplo, en ESF, donde su cronista indica:

enconadas polémicas con periódicos progresistas pero también con otros diarios católicos e incluso respecto a Obispos españoles. La relación para con la ACN de JP, en la época de Manuel Senante, fue de apoyo inicial y de ataque posterior por su supuesta deriva hacia el conservadurismo, o hacia un abandono de los principios tradicionales en aras de posturas posibilistas o accidentalistas.

49 Al indicar que los jóvenes ya «pertenecían a ella», se deduce lógicamente su preexistencia respecto a dicho acto litúrgico. Ángel Ayala, op. cit. p. 295.

50 De «confirmación solemne» habla el P. Ayala en el BACNP 1.I.1955 p. 2

51 El Porvenir los describe del siguiente modo: «Esta Asociación es una nueva verdadera cruzada de intrépidos guerreros que, sin temor al sectarismo y fiando en Dios, desplegan [sic] la bandera de la fe y recorren España entera para contrarrestar el avance del error, esgrimiendo las armas de la más pura lógica, de la argumentación más sólida y acorazados con la cruz salvadora que con orgullo santo obstentan [sic] en sus pechos en pequeña decoración, signo de su instituto", El Porvenir 16.VI.1909, p. 1. La descripción de la insignia original que llevaban en el ojal de la solapa coincide con la que hace el P. Ayala: «...blanco botón esmaltado en cuyo centro campea la cruz», F. Cervera, Ángel Ayala, op. cit.

52 Herrera Oria 2005: 135. También Herrera, en sus Memorias, justo después de exponer los primeros mítines de Ciudad Real y antes de aludir al acto de imposición de insignias del 3 de diciembre de 1909, afirma que el P. Ayala: «Formalizó jurídicamente la constitución de la Asociación». Herrera, [Memorias] s/f: 3.

53 Andrés-Gallego 1993: 253.
«El excelentísimo señor Nuncio dio existencia canónica, incorporándola a la Prima primaria de Roma, e imponiendo las insignias a sus miembros, a una nueva Congregación Mariana: la naciente Asociación católico-nacional de jóvenes propagandistas»..$^{54}$

En cualquier caso, nuevas campañas de mítines sucederían a este acto litúrgico inaugural con la bendición e imposición de insignias. La más importante fue sin duda la "gran campaña por Andalucía», como la denomina Ángel Herrera, que después de meses de preparación y organización, se inicia el 5 de diciembre con una serie de mítines en Granada por parte de Herrera y Requejo. ${ }^{55} \mathrm{El}$ plan previo para Granada era dar dos mítines preparatorios en centros católicos y un gran mitin público el día de la Inmaculada. ${ }^{56}$ Antes de su llegada a Granada, se habían enviado cartas de recomendación del Nuncio Vico para el obispo, y del Provincial de Toledo para los Luises y jesuitas de Granada, puesto que los intentos previos del P. Ayala recibieron respuestas desalentadoras en el sentido de que era una locura, que iba a ser un fracaso, o que en el día de la Inmaculada era inapropiado celebrar ningún acto semejante. ${ }^{57}$ Por si fuera poco, debido a un malentendido en las cartas entre el Nuncio y el Arzobispo pensó este último que la campaña se suspendía, mientras que el Nuncio y el P. Ayala daban por hecho que todo seguía adelante. De hecho, cuando la mañana del 4, Herrera y Requejo llegaron a la estación granadina después de toda la noche de viaje no había nadie esperándoles. Tuvieron la suerte de que en la entrevista de Herrera y Requejo con el arzobispo, ese mismo día 4, pudieron mostrar las cartas del nuncio. Una vez más gracias a la mediación de Vico, que seguía apadrinando a la ACN de JP, lograron vencer las resistencias del arzobispo, no sin advertirles éste: «Creo que lo que Vds. pretenden es francamente temerario», y les sugirió "como solución media» celebrar unas conferencias más modestas en los salones que utilizaba la Acción Católica.

54 ESF, 3.XII.1909. p. 2. Es un dato demasiado preciso y detallado como para que sea atribuible al desliz de un cronista periodístico, sobre todo cuando uno de los «jóvenes propagandistas», Rafael Rotllán, era redactor de ese periódico, siendo probable que él mismo informase de la noticia. Por otro lado, el libro fundacional del Colegio de Areneros, el actual ICAI-ICADE, la Historia Collegii et Instituti Matritensis, alude también al término «congregatione». Véase también: Nuestra Casa. Historia 75 años 1908-1984. En el 75 Aniversario de la Universidad Pontificia Comillas ICAI-ICADE. Madrid, Ediciones ICAI. 1984; o también: M. Revuelta, op. cit. p. 524. He consultado personalmente esta cuestión en el Archivo de los jesuitas en Roma (ARSI), pero no conservan listado de las congregaciones marianas españolas de aquellos años. Consultándolo con un especialista en historia de la congregaciones marianas a quien se nos remitió en el ARSI, el P. Michael Maher SJ (Saint Louis Gonzaga University, EEUU), éste se inclinaba a pensar que seguramente fuera reconocida en algún momento como congregación mariana. Por el contrario, José Luis Gutiérrez no lo considera probable.

55 Afirma Ángel Herrera: «Nos reuníamos todos los días para prepararla en Areneros, donde a la sazón residía el P. Ángel», BACNP, 95, 5.VII.1930, p. 2.

56 Para los datos de esta narración, utilizo fragmentos que estaban perdidos de las memorias de Ángel Herrera Oria y que se han encontrado en el contexto de esta investigación. Por tanto, varios de los detalles que se narran sobre la campaña andaluza son inéditos.

57 Dice Herrera en sus memorias que «Intervino directamente el Nuncio, dirigiéndose al Sr. Arzobispo, y el Padre Provincial de los Jesuitas, dirigiéndose al Superior de la Residencia de Granada». (Memorias, op. cit. p. 4). 
Ellos aceptaron pero diciendo que también visitarían a los jesuitas, según las instrucciones madrileñas. Esa misma tarde fueron a ver a los jesuitas para involucrar a los Luises, repitiendo los responsables jesuitas la misma escena de temor inicial pero de posterior obediencia ante el superior, en este caso el Provincial toledano; así como la propuesta de unas conferencias matinales de consolación al día siguiente en los salones de los Luises. Como resultado, se celebraron las conferencias ante los Luises en la mañana del 5 , con notable concurrencia, lo cual alentó la preparación de otro mitin preparatorio esa misma tarde ante el Centro de Obreros del Ave María (5.XII.1909), dirigido por el padre Pedro Manjón -sobrino del célebre Andrés Manjón--. ${ }^{58}$ Finalmente, celebraron el otro mitin-conferencia mediano, propuesto por el obispo, ante el Círculo Católico de Obreros $\left(7\right.$. XII.1909) ${ }^{59}$, que fue otro éxito. Los éxitos acumulados en estas conferencias previas propiciaron una nueva reunión en la noche del 6 en la que el arzobispo seguía algo reacio, aludiendo a la falta de tiempo para su organización, pero permitió que Herrera y Requejo tomaran la última palabra, los cuales vieron «el Cielo abierto» para su objetivo último. Así, el arzobispo, animado por el éxito de estos "ensayos», les permitió finalmente su deseo de dar un gran mitin público en el Teatro Isabel la Católica (8.XII.1909), el cual según la prensa local se saldó con un gran éxito de audiencia..$^{60}$ El diario granadino La Gaceta del Sur dedica su primera página y siguientes a la crónica del acto, con grandes titulares y a seis columnas: «La Asociación CatólicoNacional de Jóvenes Propagandistas. Mitin Monstruo. Triunfo completo». ${ }^{61}$

Después de este mitin, celebrado el 8 de diciembre, Herrera y Requejo dieron varios mítines a lo largo de su viaje por diversas provincias andaluzas: El Puerto de Santa María (9/10), Cádiz (10/12), Jerez de la Frontera, Sevilla (16), Huelva (16 o 17), de nuevo Sevilla (17 y 20) $y$, concluyendo esta serie con un último mitin en Cáceres (22). ${ }^{62}$ No me detendré en ellos porque han sido expuestos suficientemente por José Luis Gutiérrez. ${ }^{63}$ Solo añadiré que, según lo que indica Herrera en sus memorias la escena de Granada estuvo a punto de repetirse en Sevilla, pero en este caso contaron con el apoyo directo del P. José M.a Rubio -posteriormente canonizado-, a la sazón director de los

58 La Gaceta del Sur, 6.XII.1912, p. 1. La Verdad, diciembre de 1909. Las fuentes hemerográficas consultadas de esta prensa granadina se encuentran en la hemeroteca municipal de Granada.

59 La Gaceta del Sur, 7.XII.1912, p. 1. El diario hace una narración detallada de este mitin.

60 Da cuenta de ello Gutiérrez, op. cit. p. 24 y ss, que recoge una primera intervención ante la congregación de los Luises de Granada después de la misa. Cfr. BACNP n. 95, julio 1930, p. 2.

61 La Gaceta del Sur, 9.XII.1909, p. 1 y 2. Aún el día siguiente dedican otro artículo en primera página, titulado: «Impresiones del mitin». Más crítica, aunque también elogiosa, es la crónica del diario socialista La Publicidad, 9.XII.1909.

62 El itinerario de puede resultar llamativo, sobre todo en el caso de destinos más locales como Jerez y el Puerto, pero resulta lógico si se tiene en cuenta que en todas estas localidades los jesuitas tenían residencias o colegios, así como congregaciones marianas: Sevilla (1883), Puerto de Santa M.a (1898), Jerez (1904), Cádiz (1905). Huelva no estaba en el plan inicial de viaje. Revuelta, Manuel. 2008. La Compañía de Jesús en la España Contemporánea, (t. III): 522 y ss.: Madrid: UPCO. Véase también el tomo II, p. 1290 y ss.

63 Gutiérrez, op. cit. p. 26 y ss.
Luises sevillanos, que fue a recibirles a la estación y con el apoyo del arzobispo Almaraz. ${ }^{64}$ Hay que tener en cuenta que el P. Ayala había sido ordenado sacerdote en Sevilla en 1903 por lo que mantendría un fuerte contacto con los jesuitas y Luises hispalenses, lo cual seguramente le fue de utilidad en esta situación. Por lo tanto, pudieron repetir la estrategia de ofrecer un acto preparatorio de menor envergadura ante los Luises, en el Centro Católico $(16)^{65}$, y un mitin amplio poco después, aunque en este caso fueron dos: uno parece que fue al día siguiente en el Teatro San Fernando y otro el día 20, en el Teatro Cervantes, auspiciado por la Juventud Católica. ${ }^{66}$ En estos mítines sevillanos colabora activamente como organizador local José Medina Togores, amigo y colaborador de Herrera desde la etapa estudiantil de ambos en Deusto. ${ }^{67}$

Como resultado del éxito de esta gran campaña andaluza, concluye Herrera en sus Memorias: «Despertó nuestra campaña andaluza un singular entusiasmo entre todos los compañeros propagandistas de Madrid. Aumentó el optimismo comunicativo del Padre Ángel Ayala $Y$ comenzó a producirse en muchas provincias de España un movimiento de expectación ante esta actitud nueva en los católicos y ante las reacciones del público tan favorables [...]». ${ }^{68}$ Aunque también suscitó rivalidades internas dentro de la Iglesia, fundamentalmente una que más tarde supondría graves dificultades para la ACN de JP: la del Obispo de Madrid, Salvador y Barrera ${ }^{69}$, que inicialmente vio con recelo el brío, independencia y métodos novedosos de la ACN de JP. ${ }^{70}$ Además, Mons. Barrera era a la sazón director de la Acción Católica oficial de Madrid de la que era Vicepresidente el Marqués de Comillas, movimiento que dependía de la "Junta Central de Acción Católica» presidida a nivel nacional por el Primado de Toledo desde

64 Por error Herrera alude en sus memorias al cardenal Spínola como Arzobispo en aquel momento pero este había fallecido en 1906, por lo que tuvo que ser Enrique Almaraz, Arzobispo de Sevilla entre 1907 y 1920, el cual además escribe carta de felicitación a los conferenciantes el mismo día por el "éxito brillante» cosechado en el mitin del 20.XII.1909. Cfr. Andrés-Gallego 1993: 289. Para el dato de las Memorias de Ángel Herrera, p. 11.

65 El correo de Andalucía, 17.XII.1909, p. 1. Agradezco a Enrique Belloso el envío de esta referencia. Del mitin del 17 solo hemos encontrado referencia en las memorias de Ángel Herrera.

66 Hay cierta disparidad en Ángel Herrera en el detalle de la fecha del mitin de Huelva. Este mitin no estaba en el plan previsto pero parece que fue empeño del Arcipreste el P. Manuel González, amigo del P. Ayala. Según narra Herrera en sus memorias, el acto de Huelva se hizo en el mismo día 16 por la noche, regresando al día siguiente temprano para la otra conferencia prevista en el Teatro San Fernando. En otro testimonio, dice que el mitin de Huelva fue al día siguiente de la llegada a la estación, cfr. Gutiérrez de sus Obras Completas, vol. I, p. 294. Para el mitin del día 20, ESF, 21.XII.1909, p. 1; La Vanguardia, 21.XII.1909, p. 8.

67 Posteriormente Medina sería subdirector de El Debate y secretario general de la ACN de P. Herrera pensó en él como sucesor suyo al frente de El Debate pero falleció antes. Para la colaboración de ambos en Deusto, véase: Sánchez Garrido 2016.

68 Memorias, A, op. cit. pp. 15-16.

69 Herrera también señala como otro punto de oposición interna a algunos sectores carlistas que temían la posibilidad de que se constituyera un nuevo partido católico de derechas. Desde Bilbao también surgió la oposición, esta fundamentalmente contra Urquijo, de grupos mauristas unidos en torno al diario El Pueblo Vasco. Memorias A, p. 17.

70 El obispo Barrera también señaló su disconformidad por el hecho de que la ACN de JP se fundara en Madrid sin su autorización, como recoge Andrés-Gallego. 
1903 por expresa designación pontificia. ${ }^{71}$ Como se verá más adelante, este prelado estuvo detrás de las gestiones que acabaron con el traslado del P. Ayala a Ciudad Real y con el intento de neutralizar la pujanza de El Debate a favor del diario El Universo, periódico vinculado orgánicamente a la Junta Central de Acción Católica a través de su patrocinador, el Marqués de Comillas. ${ }^{72}$ Las relaciones entre la ACN de JP y la Acción Católica presidida por Mons. Barrera y por el Marqués de Comillas, fueron inicialmente tensas, aunque Herrera reconoce que, sin embargo, años más tarde, ya como Arzobispo de Valencia, el prelado acabaría trocando su recelo inicial en apoyo decidido e incluso protección hacia la ACN de JP. ${ }^{73}$ Puede que uno de los motivos del recelo hacia la naciente ACN de JP, además de la menor sintonía de esta con la opción dinástico-conservadora, fuera la similitud

71 La organización inicial de Acción Católica española, sobre la base de los Congresos Católicos, fue encomendada por León XIII al obispo primado en 1903 (v. Carta Quos nuper), -entonces cardenal Sancha y a sus sucesores-, constituyéndose en una Junta Central en Madrid y en comisiones o juntas diocesanas regionales. Cada pontífice ratificaría la dirección de la Acción Católica a los sucesivos primados, incluyendo a Pío XI con el cardenal Segura (carta del 7.II.1928). Esto fue así hasta que se produjo la histórica «reorganización» de la Acción Católica española por indicación expresa de Pío XI al cardenal Segura (carta Laeuts sane nuntius, 6.XI.1929), que desembocó en el famoso documento de la Conferencia de Metropolitanos de 1931 liderada por Vidal y Barraquer: «Bases para la reorganización de la Acción Católica española» y en el nombramiento de Ángel Herrera como Presidente de la Junta Central. Véase: Cardenal Gomá, «Informe sobre la Acción Católica en España por el Card. Gomá al Card. Pizzardo», en José Andrés-Gallego (ed.), 2006, Archivo Gomá: documentos de la Guerra Civil, Volumen 10, Madrid: CSIC.

72 El Universo, dirigido inicialmente por Juan Manuel Ortí y Lara, fue fundado en 1900 y vinculado desde 1902 a la Acción Católica que en la diócesis de Madrid era presidida por el Obispo de Madrid y por Claudio López Bru, marqués de Comillas, el cual llegó a sufragar personalmente los gastos del rotativo. En 1926 pasó a ser semanario y a denominarse: «Revista de Acción Católica y Cultura General». Cfr. Giorgio Papasogli, El marqués de Comillas: Don Claudio López Bru, UPCM, Madrid, 1984, p. 132. También hay una tesis de Enrique Faes sobre López Bru, (UNED, 2006). Para la vinculación oficial del diario con la Junta Central de Acción Católica puede verse la carta que remite su entonces director en 1911 al Obispo de Madrid: «El que suscribe, director de El Universo, diario católico que se publica en esta Corte, con censura y licencia eclesiásticas y bajo el patrocinio de la Junta Central de Acción Católica...»; más adelante afirma: "Y a este efecto, más de veinte prelados reunidos en Madrid con el Señor Nuncio de Su Santidad, en el mes de junio de 1902, acordaron rogar a la Junta que se encargase de la publicación de este periódico, sin que hasta la fecha los señores prelados hayan relevado de aquel encargo a la corporación citada. Y desde entonces El Universo se publica bajo el patrocinio de la Junta Central de Acción Católica, y de ella recibe constantemente inspiraciones, a las cuales se ajusta con escrupulosidad y esmero». Esta carta de 13.IV.1911 se encuentra en el Archivo de la Compañía de Jesús en Roma, ARSI, Tolet, 1003, XI, 1, p. 1.

73 Herrera señala respecto a este grupo de Acción Católica, que se reunía todos los jueves en la casa del Marqués de Comillas contando con la presidencia directa del Obispo, que: «En este grupo la reacción fue de sorpresa y disgusto. Y quedó muy alerta para seguir las incidencias de este nuevo movimiento católico que actuaba con procedimientos nuevos y con una extraordinaria independencia», Memorias A, p. 16. Muy probablemente, el joven Herrera expuso las circunstancias en su audiencia ante san Pío $X$ pues lo principal que este le pidió que transmitiera fue: «Decid de mi parte al Sr. Obispo: «lo vi racomendo a lui». Cuando Herrera le comunicó esto al prelado contestó que «Vds. no necesitan recomendación, Vds. se recomiendan solos». Esto fue un año después de la fundación. A su vez, expone Herrera que con el tiempo, una vez nombrado Arzobispo de Valencia (1916): «fue nuestro protector en varias ocasiones». Memorias A, p. 19. Corrobora este dato el P. Ayala en 2002: 880 . o solapamiento que veía el prelado diocesano entre los propósitos últimos que tenían ambas organizaciones, incluyendo la fundación de sendos diarios que anhelaban asumir la representación oficial del catolicismo. A ello se unía el apoyo decidido del nuncio hacia los propagandistas en detrimento de la Acción Católica liderada por el Marqués de Comillas. ${ }^{74}$ Años más tarde, ambos movimientos se unirían en la práctica cuando se produjera la reestructuración de la Acción Católica en 1931, precisamente en la persona de Ángel Herrera Oria, como presidente de la Junta Central de Acción Católica.

Otro hecho que no se ha recogido con anterioridad es que en paralelo con la gran campaña de mítines por Andalucía, hubo otras salidas para dar mítines los días 6 y 8 de diciembre de 1909, en Ávila y Alcalá de Henares. En efecto, el día 6 de diciembre, mientras que Herrera y Requejo estaban en Granada, también hubo otro mitin de la ACN de JP en el Teatro Principal de Ávila, que dieron los propagandistas Gómez-Roldán, Aristizábal (no se especifica si Luis, o su hermano José Manuel), y Mateo de la Villa. ${ }^{75}$ Por otro lado, el mismo día 8 de diciembre, festejo de la Inmaculada, mientras que Herrera y Requejo conseguían dar su gran mitin en Granada, hubo otro en el Centro de Acción de Social de Alcalá de Henares por parte de los propagandistas: Luis Castel, Rafael Rotllán y Jaime Chicharro; los dos primeros, de la nueva hornada incorporada el 3 de diciembre. Castel habló de la beneficencia católica sobre la infancia, Rotllán criticó el materialismo ateo y ensalzó el idealismo católico; mientras que Chicharro hizo un encendido alegato para la movilización de los católicos, principalmente en el campo electoral. ${ }^{76}$

\section{LA PROPAGACIÓN DE LAS CAMPAÑAS DE MÍTINES EN 1910: PRI- MERA EXPANSIÓN DE LA ACN DE JP}

El año 1910 fue muy intenso en términos políticoreligiosos porque el comienzo del año casi coincidió con la Ilegada al Gobierno de Canalejas (9.II.1910), tras la dimisión de Moret. En 1910 se llevaron a cabo diversas medidas anticlericales: se propuso la retirada del embajador español del Vaticano (30.VII.1910); se preparaba la que se llamó "Ley del Candado" y el decreto de reapertura de las escuelas laicas ${ }^{77}$-varias de estas iniciativas se iniciaron ya con Moret-. Todo ello dio lugar a intensas manifestaciones de los sectores católicos en contra de lo que se interpretaba como afrentas contra la Iglesia. Tampoco hay que olvidar que

\footnotetext{
74 Al parecer el nuncio encargó al P. Ayala la reorganización de la Acción Católica pero comenzando por la juventud, quizá para evitar rivalidades con la Acción Católica establecida en Madrid dependiente del Obispo Salvador y Barrera con el que el nuncio tuvo importantes desencuentros. Esto fue la base de la organización que emprendió la ACN de JP y Herrera años más tarde de la Juventud Católica. Sobre esto véase: Watanabe, Chiaki. 2003. Confesionalidad católica y militancia política: Ia ACN de P y la Juventud Católica Española (1923-1936): Madrid: UNED.

75 ESF, 6.XII.1909, p. 2.

76 ESF, 9.XII.1909, p. 1.

77 Los acuerdos del Gobierno de Canalejas fueron tomados por el ministro de Instrucción Publica, Antonio Barroso y se interpretaron como "una bofetada a las altas dignidades de la Iglesia», tras lo cual algunos católicos reclamaban ir en su contra en "guerra sin cuartel contra los enemigos de la escuela católica», como se arengó desde La Gaceta del Norte, 4.II.1910, p.1., Cfr. Robles 1997: 231.
} 
unos meses antes del comienzo de 1910, había tenido lugar la Semana Trágica en Barcelona tras la cual se recrudeció la crisis del gobierno maurista que condujo a que el rey aceptara su dimisión. Por otro lado, la situación sociológica del catolicismo seguía siendo de un fuerte enfrentamiento entre sus sectores más políticos, junto a una anomia o pasividad entre sus masas sociales. ${ }^{78}$

Ante este contexto, los propagandistas, alentados por el P. Ayala emprendieron nuevamente intensas y extensas campañas de mítines de protesta por diversos lugares de España durante todo el año 1910, siendo este grupo el que propició, coordinó y lideró de modo principal la sonada reacción social del movimiento católico durante ese año. El doble objetivo era despertar a las masas católicas y unir a los distintos sectores políticos del catolicismo a partir de un frente común contra las medidas anticlericales del gobierno en el que cupieran desde los integristas hasta los católicos dinásticos y conservadores. Pero 1910 fue un año crucial para la ACN de JP en otro sentido, ya que iba a ser el año en el que se decidiría su crecimiento y consolidación inicial para convertirse en una asociación de alcance auténticamente nacional. En este año se iba a demostrar si sus primeros éxitos eran flores de un día o si lograba crear un movimiento catalizador del movimiento católico en la esfera social y pública.

En cuanto a la clasificación temática concreta de los dos grandes mítines que dieron en el Jai-Alai y de los restantes mítines del año 1910, pueden agruparse en dos cuestiones fundamentales: la principal fue el combate al anticlericalismo, fundamentalmente en la propuesta de la Ley del Candado y en la reapertura de las "escuelas laicas»; junto con algunos dedicados al tema católico-social, que sería el tema principal en años posteriores. Igualmente, intercalaban mítines en los que daban a conocer a la ACN de JP.

Después de la campaña «inaugural» andaluza de finales de 1909 hubo dos mítines de gran repercusión organizados por la ACN de JP en 1910, ambos en el famoso frontón Jai-Alai de Madrid. El primero, el 2 de febrero de 1910 y el segundo, aún más multitudinario, el 2 de octubre. Para ambos, la estrategia de ir dando mítines preparatorios previos, estrategia que había ensayado exitosamente en los mítines andaluces, se repitió pero amplificada temporal y espacialmente. ${ }^{79}$ La celebración de actos previos se extendió por diversas provincias y localidades por parte de otras organizaciones eclesiales, que asumieron la organización de los actos provinciales y locales, tanto de los preparatorios como de las réplicas de adhesión que se celebraron el mismo día de ambos actos.

Con esta estrategia, el mitin del día 2 de febrero contra la reapertura de las escuelas laicas por Moret fue multitudinario. El $A B C$ dedicó la foto de portada y otra foto de página completa a la concurrencia del acto, así como una minuciosa crónica del mitin y la reproducción del discurso de

78 Sobre este tema pueden verse los informes previos de Vico sobre los católicos españoles durante su etapa de secretario del anterior Nuncio español, recogido en Cárcel Ortí 1988.

79 Este mitin fue precedido de otros tres preparatorios, que se celebraron en el Centro de Defensa Social, por parte de Aristizábal, Henestrosa y Palanco (28.I.1910); en el Círculo Católico de Obreros, por Chicharro, Villa y Palanco (30.I.1910) y en el teatro Príncipe Alfonso (30.I.1910), con Gómez-Roldán, Montalvo, Requejo, Aristizábal y Rotllán. Cfr. ESF, 28 y 31.I.1910, p. 1 y en 1.II.1910 se habla de otro en el Centro de Defensa Social el 31 de enero, p. 8; Seglares... p, 41. adhesión de Menéndez Pelayo. ${ }^{80}$ Contó con la participación en la tribuna presidencial de los propagandistas fundadores: Bofarull -en representación de la Juventud Carlista-, Montalvo -por los Luises-, Gómez-Roldán -por la ACN de $\mathrm{JP}$, como secretario del acto- y de Requejo, como orador. Ángel Herrera no participó, ni siquiera como orador. ${ }^{81}$ Se contó con la representación de las diversas fuerzas católicas, desde las conservadoras -con Valentín Gamazo, de la Juventud Conservadora- y con Martín Lázaro por el Centro Defensa Social -vinculado al Marqués de Comillas-, hasta las integristas. Además, contó con la bendición del Primado Aguirre, que envió un texto de adhesión, y con la representación del Obispo de Madrid en la persona de Luis Bahía - de la Junta Central de Acción Católica-, al que además se le concedió presidir el acto. Para finalizar, se leyó el texto de Menéndez Pelayo defendiendo la escuela católica y señalando las deficiencias de la escuela laica. ${ }^{82}$ Este acto y las diversas movilizaciones paralelas de ese mismo día y de los previos fueron una demostración de fuerza por parte de la opinión católica y el propio rey, en una audiencia con el nuncio tres días después, habló de la importancia de estas movilizaciones católicas para la incidencia sobre la política religiosa nacional. ${ }^{83}$

Ante el éxito cosechado se repitió la jugada para el otro gran mitin del Jai-Alai el 2 de octubre, pero con una preparación durante meses considerablemente más amplia y logrando una asistencia el triple mayor. A propósito de los actos preparatorios de este acto, ya puede verse cómo se iban uniendo nuevos miembros a la ACN de JP, como José López de Vívigo desde Valladolid. ${ }^{84}$ Este nuevo propagandista organizó en Asturias la campaña regional de mítines preparatorios y de manifestaciones contra el laicismo del gobierno en adhesión al mitin de octubre. Una serie de conferencias por toda Asturias fueron preparando el terreno desde el mes anterior, como la de Gerardo Requejo el 17 de septiembre, en el Centro de Acción Social; la del 18 y 19 de septiembre de Herrera y López Vivigo ante un grupo de mujeres en Gijón; y otra mucho más amplia al día siguiente a la que se unió Francisco Cuervo. ${ }^{85}$ Nuevamente,

$80 \quad A B C, 3 . I 1.1910$, pp. 1-2 y 7-9.

81 Una explicación de su ausencia es la hipótesis que planteamos en este artículo de que el año 1910 lo pasó en la casa familiar de Santander que usó como centro de sus operaciones en el norte de España.

82 J. M. a Urquijo organizó igualmente mítines similares en el entorno vasco durante los meses de febrero, marzo y abril, y pasa a defender desde las páginas de GN la necesidad de llevar la política al mitin ante el conflicto de las escuelas laicas. Se trataba de aprovechar el conflicto para organizarse, lo cual daría lugar a la Junta católica de Vizcaya, que sería el núcleo de otras nuevas por toda España. Robles 1997: 232 y ss. y 246

83 Cfr. Robles 1997: 245.

84 Sobre este dice «[...] Herrera y Vívigo que forman parte de ese conjunto de jóvenes ilustres y virtuosos, batalladores incansables en la propaganda de las ideas católicas [...]», antes alude a las campañas de estos propagandistas por las Castillas, Andalucía, etc. El Principado, 19.IX.1910. El mismo diario alude a la preparación de la manifestación por parte de «los jóvenes propagandistas Vivigo y Cuervo», El Principado, 21.IX.1909.

85 El Principado, 19.IX.1910, p. 1. ESF20 y 21.IX.1910. Curiosamente, en El Siglo Futuro ya no se detallan con tanto énfasis las palabras de Herrera, o Vívigo "como jóvenes propagandistas», sino de las de F. Cuervo, a quien Ilaman «correligionario». Es sabido que El Siglo Futuro pasó del amor hacia la ACN de JP al odio, algunos años después, quizá comenzaron a manifestarse discrepancias con cierta anterioridad 
volvieron a actuar Herrera, Vívigo y Cuervo en Gijón hacia el 30 de septiembre ${ }^{86}$, y dieron otros mítines por la región, como los de Avilés (25.IX.1909) y Villaviciosa (28.IX.1909) ${ }^{87}$, etc. Actos que culminarían con una amplia manifestación en Oviedo como adhesión al mitin madrileño.

Se secuenciaban por tanto los mítines preparatorios desde lo local, a lo regional para finalmente potenciar el mitin nacional en Madrid. Otros mítines preparatorios del "mitin monstruo» de octubre, ya de nuevo en Madrid, fueron los del 27 de septiembre en el Centro Social del ICAI, por parte de Mateo Villa y Herrera; y el del 29, en los Luises, por parte de Fernández de Henestrosa, Palanco y Herrera. ${ }^{88}$ Para amplificar asimismo el efecto social y mediático de este mitin central, también durante el mismo día 2 de octubre se celebraron al mismo tiempo manifestaciones, mítines de réplica, "aplechs», así como eucaristías y actos de desagravio en distintos lugares de España. ${ }^{89}$

Por su parte, Ángel Herrera, que a la vuelta de su campaña andaluza seguramente pasó la Navidad de 1909 en su Santander natal junto a su familia, no perdió la ocasión de dar un mitin en el Círculo Católico de Santander para presentar allí la ACN de JP el 2 de enero de 1910, o un par más en Valderredible (Santander), el verano del mismo año. ${ }^{90}$ Estos mítines en el valle cántabro motivaron una posterior entrevista entre Herrera y Antonio Maura en la que aquel le expuso la situación del intenso caciquismo político, así como la falta de representación electoral de pueblos enteros de la región. ${ }^{91}$

Asimismo, Herrera participó desde Santander en la campaña de mítines contra las escuelas laicas que se organizó conjuntamente para la tarde del 27 de febrero de 1910 en diversas ciudades españolas, como el de Bilbao, organizado por los Luises -en el que hubo ciertos alborotos de grupos contrarios que se introdujeron en el acto provocando la posterior intervención policial- y San Sebastián. Hubo otro en Santander, convocado por el Consejo diocesano de corporaciones católico-obreras y presentado por Ángel Jado, que contó con la intervención

86 ESF 30.IX.1910, p. 1. En su discurso, López Vívigo afirmaba que quería crear «una sección de la

Juventud propagandista, fundada en la Congregación de la Inmaculada Concepción».

87 El Principado, 28 y 30.1 X.1910, p. 1

${ }^{88}$ ESF 30.IX.1910, p. 1. Se anuncia otro para el 30 en el Centro de Defensa Social, por parte de Montalvo, Aristizábal, y Rotllán, en ESF 28 y 30.IX.1910, respectivamente, p. 1.

89 Para una referencia a la movilización en diversas ciudades, véase El Principado, 3.X.1910.

90 En ESF se informa de varios mítines de Herrera para este centro electoral en Gama y Torrelavega, ESF, 6.VIII.1910, p. 2.

91 El Diario Montañés, 2.I.1910. Se informa de ello en una carta al director de ESF desde Santander, indicando el autor que El Diario montañés del mismo día ha dado información del acto. ESF, 8.I.1910. En el verano de 1910 Herrera dio dos mítines en Polientes (Santander) en protesta contra el hecho de que no hubiera votaciones en los pueblos del Valle de Valderredible y que las actas electorales se rellenasen desde el Gobierno Civil de Santander. Hubo un primer mitin coordinado incluso con el Partido Republicano y otros dos desde el Centro Electoral Católico en los que participó Herrera. Ya en Madrid, Herrera se entrevistó con Antonio Maura para informar de los hechos, el cual, lejos de sorprenderse, señaló que esa era la misma situación de otros muchos lugares de España y que era un problema de falta de conciencia religiosa en la burguesía española. En sus memorias, Herrera insiste en el impacto que le produjo este suceso, cfr. Gutiérrez, op. cit. p. 66-69. de Herrera junto a los propagandistas fundadores Montalvo y Palanco, así como un tal Zaldo Ortiz. ${ }^{92}$ El mismo Jado sería el organizador en Santander de la junta convocante del mitin de adhesión al gran mitin nacional del Jai Alai, sobre el cual, según recoge J. de la Cueva: «El 2 de octubre tuvo lugar la mayor manifestación católica que haya conocido la Montaña: dieciséis mil manifestantes en Santander y setenta mil en toda la región, según cifras de El Diario Montañés [...]». ${ }^{93}$

Por otro lado, en el continuado anuncio del mitin que se iba a dar el 20 de febrero en Vitoria por parte de Herrera y que iba a unir a carlistas, conservadores, Luises y Juventud Católica, se habla ya de la existencia de la «Sección Vitoriana de la ACN de JP». ${ }^{94}$ Un día antes, el 19 de febrero, Herrera daría otro mitin sobre la naturaleza de la ACN de JP, en el que señalaba que la Asociación estaba dividida en 3 secciones: oradores, representantes en las obras sociales y periodistas -una división que no aparece en los estatutos de aquellos años- ${ }^{95}$ Estos anuncios insistentes de este mitin monstruo regional en los días e incluso semanas anteriores muestran la deliberada estrategia mediática de ir anticipando la noticia en diarios regionales y municipales afines para "caldear el ambiente», estrategia que se unía a la de la adhesión mediática de otros diarios de regiones colindantes para propiciar un efecto contagio en las zonas próximas.

Este importante mitin regional de Vitoria monopolizó las energías del mes de febrero aunque con algunas excepciones. ${ }^{96}$ Pasando al mes de marzo, el día 2 de marzo de 1910, Herrera da una conferencia en la Universidad de Deusto (Bilbao), su alma mater, con el tema: la ACN de JP. ${ }^{97}$ En Valladolid se celebró el 6 de marzo un mitin en el Teatro Calderón contra la reapertura de las escuelas laicas, en el que participan Herrera y Requejo. ${ }^{98}$ Este mitin fue importante porque seguramente preparó el terreno para la creación del Centro de Valladolid, cuyo primer secretario fue Rafael Torrecilla. A este nuevo propagandista, lo encontramos por primera vez en el mitin próximo al 20 de abril en Palencia, donde -aunque hablando por los Luisesaparece junto a los propagandistas López Vívigo y José Manuel de Aristizábal. ${ }^{99}$ Volverá a aparecer Torrecilla en Peñafiel, el 20 de noviembre de 1910, en otro mitin sobre la ACN de JP. ${ }^{100}$

Una nueva tanda de mítines andaluces por tierras sevillanas pondrían las bases, en la primavera de 1910, de la constitución del centro de Sevilla, otro de los centros pioneros de la ACN de JP, cuyo co-fundador y puede que primer secretario, fuera Juan Colomer, otro de los jóvenes

\footnotetext{
92 ABC, 28.X. 1910, p. 11.

93 Cueva 1910: 93.

94 Heraldo Alavés, 14.Il.1910, p. 1, también el 15, 16, 17, 18 y 19.

95 Ibídem. Día 19. Incluye crónica detallada de la intervención de
} Herrera.

96 Como ejemplo, la ACN de JP colabora a través de Herrera y Requejo en la creación de la Juventud del Círculo de la Inmaculada en Burgos. La voz de Castilla, 22.II.1910, p. 2.

97 Heraldo Alavés, 2.III.1910, p. 1, sobre la ACN de JP, y otra en Deusto el 3.IV.1910, contra las escuelas laicas, ESF, 3.IV.1910, p. 1.

$98 \quad A B C, 7.111 .1910$, p. 8. Otro mitin vallisoletano de la ACN de JP el 28.III.1910 en Medina del Campo, fue interrumpido por alborotadores, en Seglares en la historia... p. 40.

99 ESF 22.IV.1910.

100 ESF 21.XI.1910, p. 2. 
propagandistas fundadores. ${ }^{101}$ Entre estos mítines puede destacarse el de José Palanco y el del «Señor Vela»-quizá Villa- de los «jóvenes propagandistas de Madrid», a finales de abril en Sevilla ${ }^{102}$; así como otro en Andújar (Sevilla) el 5 de junio, en el que interviene Chicharro, aunque también participan otros futuros propagandistas sevillanos, como José Medina Togores -cofundador del Centro, redactor Jefe de El Correo de Andalucía y futuro subdirector de El Debate- y José Illanes. ${ }^{103}$ Algún tiempo después se iniciaría la colaboración formal entre ambos diarios católicos, hermanados por la Editorial Católica (EDICA), creada por la ACN de JP en 1913.

Otros propagandistas continuaron celebrando intensas campañas de mítines por el territorio nacional entre abril y junio de 1910: a mediados de abril, Herrera en Orduña (Vizcaya) ${ }^{104}$; 15 de abril, en Córdoba, por parte de GómezRoldán y Fernández de Henestrosa ${ }^{105}$; el 17 de abril en Ciudad Real, por Lamamié de Clairac ${ }^{106}$; el 18 de abril, en Segovia, por parte de Montalvo, Gómez-Roldán y Villa ${ }^{107}$; en Ávila, el 5 de mayo, por parte de Fernández de Henestrosa y Cavengt. ${ }^{108}$ No contamos aquí los innumerables mítines que estaban igualmente relacionados con la protesta de octubre pero que no fueron protagonizados por los miembros de la ACN de JP, como los vinculados a las Juntas Católicas, porque su número es enorme y se sale de nuestro tema específico.

Otro lugar destacable será Murcia, cuyo centro se estaba intentando constituir por estas fechas en torno a su futuro secretario, Francisco Sigler. Allí, se da un mitin contra las escuelas laicas ante cinco mil personas el 5 de junio, en el que participan Mateo de la Villa, Aristizábal y Palanco. ${ }^{109}$

A Galicia llega el 3 de junio Herrera, donde comienza una amplia campaña de mítines que le llevará varios meses de verano, entre Galicia, Asturias y Castilla. Llama la atención también la capacidad que tenía Herrera y los otros jóvenes propagandistas de coordinarse con otras organizaciones católicas como se señala a su llegada a Galicia: Juventud Católica, Apostolado de la Oración, Patronatos Católicos, Juventud Antoniana, etc. ${ }^{110}$ La campaña gallega da comienzo

101 En el expediente del propagandista fundador Juan Colomer él indica de su puño y letra que fue "Secretario fundador del Centro de Sevilla con Pepe Medina (e.p.d.), Illanes, L. Villavicencio (¿்), L. Bermudo (¿), Ayala, Pavón, Sanz, etc. Por los años 1912 o 1913. Entonces tenía 33 años. Expediente en AHACP. En La Correspondencia de España (8.XII.1913), p. 2, aparece presidiendo un mitin que imparten Herrera, Requejo, e Illanes y Medina, donde se indica que es presidente de la Juventud Católica.

10225 de abril, ESF 25.IV.1910, p. 1; el 24, Vela contra las escuelas laicas en el Teatro San Fernando, La correspondencia de España, 25.IV.1910, p. 4.

103 ESF, 9.VI.1910, p. 1. También intervinieron en Osuna, Dos Hermanas, Écija...

104 La Hormiga de oro, 23/4/1910, p. 9. No se consigna fecha exacta solo aparece foto de Herrera en el mitin.

105 ESF 16.IV.1910, p. 2.

106 ESF, 18 y 19.X.1910, p. 2. Habla de dos mil asistentes, muchos de ellos "forasteros», y de diez mil adhesiones.

107 ESF 16.IV.1910, p. 2. También se menciona el de Ciudad Real, por Palanco y Lamamié. Se refiere igualmente el segoviano en La Correspondencia de España, 18.IV.1910, p. 3

108 ESF, 6.V.1910, p. 1. También en La Época, 06.V.1910, p. 1. Contra las escuelas laicas.

109 ESF 7.VI.1910, p. 1.

110 También se informa en el coruñés El Noroeste, 4.VI.1910, p. 1. en el Teatro Principal de La Coruña, el 5 y 6 de junio ${ }^{111}$; al cual se añade otro calificado como "mitin monstruo», el 7 de junio en Betanzos ${ }^{112}$, el 8 en La Coruña ${ }^{113}$, el 9 en Ferrol ${ }^{114}$, el 12 en Lugo $^{115}$, el 21 en Santiago ${ }^{116}$... El 31 de julio, nuevamente aparecen Palanco y Herrera dando un mitin junto a la Juventud católica en el pueblo de Cabuérniga (Cantabria). ${ }^{117}$

Pero, a principios de septiembre Herrera se dirige a Zamora para reanudar la gira de mítines regionales por la zona norte de Castilla, orientada a potenciar el mitin de octubre y a formar "juntas de defensa católica», como la existente en Vizcaya, creándose en aquel mitin del día 13 la Junta de Zamora. ${ }^{118}$ Se trataba con estas juntas de aprovechar la resonancia de los mítines a través de la creación de una red de Juntas católicas de defensa en las principales ciudades y provincias españolas. La Junta de referencia fue la de Vizcaya, creada entre junio y julio de 1910 y presidida por el líder católico y director de La Gaceta del Norte (en adelante, LGN), José M. a Urquijo. ${ }^{119}$ La Junta de Vizcaya, junto con la de otras provincias vascas y navarras, comenzó como órgano organizativo de la campaña de manifestaciones y mítines de febrero contra el laicismo educativo. La idea de Urquijo era "hacer algo aquí que resuene en toda España». ${ }^{120} \mathrm{El}$ acto programado fue un mitin monstruo en Bilbao para julio que fue prohibido por el gobierno ante el temor de que el movimiento de oposición se contagiara a otras zonas, alegándose como pretexto los altercados de la huelga minera de Vizcaya. Como consecuencia de la prohibición encubierta, el encuentro se trasladó a San Sebastián el 7 de agosto de 1910. El gobierno de Canalejas, cada vez más alarmado por la expansión de esta movilización católica, intentó que el nuncio lo suspendiera y finalmente tomó militarmente la zona, prohibiendo la manifestación y con el traslado del Ministro de Gobernación a Bilbao. Finalmente la Junta tuvo que suspender la manifestación ya que muchos de sus dirigentes fueron detenidos y la Junta católica fue

111 También el 5 de junio de 1910 en el Salón del Patronato católico de San José; tema: Las escuelas laicas. 6 de junio, La Coruña (ibídem), tema: la ACN de JP, El Noroeste, 05.VI.1910.

112 ESF 8.VI.1910, p. 1. En dicho mitin se protesta de la reapertura de la escuela laica de la Corana, que acordó el Consejo de Instrucción pública, aprobando un dictamen del señor Vincenti. La Vanguardia, sábado 4.VI.1910.

1138 de junio en La Coruña, tema: acción social católica y organización socio-electoral de los católicos, El Noroeste, 09.VI.1910. Se anuncia que Herrera anula los mítines proyectados en Ferrol y Santiago y que vuelve a Madrid, cosa que no ocurre finalmente.

114 ESF, 8.VI.1910.

115 Tema: la organización de los católicos. El Progreso, (10, 11 y 12 / VI/1910) y El Salmantino, 13.VI.1910.

116 En el patronato de los Luises de Santiago, El Eco de Santiago, 22.VI.1910, p. 2 y El Noroeste, 21.VI.1910, p. 1.

117 Revista Cántabra, 6.VIII.1910I, p.10.

118 El Salmantino, 13.IX.1910, p. 2. Se anuncia para el 4 de Septiembre un mitin suyo en Laguardia. El Eco de Santiago, 3.IX.1910.

119 Para una biografía muy completa de este importante colaborador esencial de la ACN de JP de los primeros tiempos, véase su biografía realizada por Cristóbal Robles, José M. a Urquijo e Ybarra. 1997. El autor se sirvió del archivo de J. M. a Urquijo que contenía una correspondencia y documentación muy nutrida respecto de la ACN de JP, no obstante, dicho archivo se quemó en su mayor parte hace unos años, según nos informó personalmente uno de su descendientes. La Gaceta del Norte fue el hermano mayor de El Debate.

120 Cfr. Robles 1997: 247. 
procesada, incluyendo al propio Urquijo. El resultado fue una victoria pírrica para el gobierno de Canalejas, que desgastó su imagen liberal y potenció indirectamente la figura de Urquijo y de su proyecto de crear una Junta Nacional de Defensa Católica y Juntas Provinciales. ${ }^{121}$ En agosto, el P. Ayala le ofrecía a Urquijo la colaboración de los propagandistas para este proyecto. Dentro de la Jerarquía contaban con el favor del nuncio y del primado Aguirre -este último también apoyaba a la ACN de JP-; en su contra estaba el obispo de Madrid. ${ }^{122}$

El hecho del gran número, variedad y proximidad cronológica de los mítines que Herrera da por toda la zona norte de España durante 1910 -especialmente, Santander, Asturias, País Vasco, norte de Castilla y Galicia-, y su conexión con el epicentro vasco de las Juntas, nos permite plantear la hipótesis de que durante ese estratégico año de 1910, Herrera seguramente estableció como residencia y centro de sus operaciones en el norte de España la casa familiar de los Herrera en Santander. ${ }^{123}$ A favor de ello también estaría el título de uno de los epígrafes que figuran en el índice de sus inacabadas Memorias, en el que escribió: «1910: Residencia Santander». ${ }^{124}$

En agosto, se intensifica la participación de algunos propagandistas en la organización de la llamada «Coalición Antiliberal», si bien como miembros «independientes». ${ }^{125}$ Posteriormente, el P. Ayala abogaría por retirar la denominación "antiliberal» para favorecer la presencia de los conservadores; aunque el mismo Ayala había definido el término «antiliberal» tan solo como «la absoluta independencia en la organización de los católicos respecto a los liberales», es decir, lo entendía como iliberal más que como propiamente anti-liberal. ${ }^{126}$ Se trataba de una coalición de católicos de diversas tendencias con vistas a lograr alguna representación y a la posterior "unión electoral católica española» propugnada desde la Santa Sede. ${ }^{127}$ Aunque Juntas y Coalición eran iniciativas similares se trataba de entidades diversas, pese a que a veces se las ha confundido, incluso con otras juntas similares existentes años atrás. Pero no obstante, hubo en 1910 una cierta acción paralela entre Juntas y Coalición, conectada bajo la figura de Urquijo, que

121 Incluso la prensa contraria del Trust se opuso a la actitud de Canalejas de impedir este mitin pues se debía «dejar ejercer el derecho de manifestación», Heraldo de Madrid, 3.VIII.1910, 1.

122 Cfr. Robles ibídem.

123 Como he indicado antes, Herrera da mítines en Santander sucesivamente en enero, febrero, marzo y agosto. Además no da ningún mitin en el sur de España durante 1910 y no asiste al gran mitin del Jai Alai en febrero.

124 También pudo influir en la posibilidad de que permaneciese durante 1910 en la casa familiar de Santander el hecho de que al fallecer en enero de 1910 su hermano José María en la misma ciudad, decidiera permanecer en ella apoyando a sus padres durante un tiempo.

125 En una carta sobre la unión de los católicos, señala Urquijo que toda movilización que quiera tener repercusión al menos debe contener una representación de los principales grupos católicos entonces actuantes: independientes (entre los que se suelen incluir los miembros de la ACN de JP y el propio Urquijo), dinásticos, integristas y carlistas. Cfr. Conde 2011 (Ed):120 y ss.

126 Cfr. Robles 1991b: 48.

127 Para un análisis de la liga de Sevilla, creada por el Cardenal Spínola en 1901, en la que participaron futuros propagandistas, como Medina Togores, véase: Ruiz Sánchez 1996: 107 y ss. Para la propuesta de la «unión electoral católica española» en 1908, véase el artículo de $\mathrm{F}$. Montero (1992) antes citado. fue convergente en diversos niveles, sobre todo a efectos del apoyo al mitin anticlerical de octubre en el Jai Alai. En este sentido, Fernández de Henestrosa aparece ya en agosto de 1910 en Burgos formando parte, como miembro de la ACN de JP, de una reunión preparatoria del mitin de octubre por parte la junta de la "Conjunción Católica Antiliberal». Pero la reunión se centró en el desarrollo de la «Federación Católica Antiliberal» para la región de Burgos, que buscaba en la región castellana una unión de carlistas, integristas "y toda clase de católicos independientes en política». Pero en la reunión se alude igualmente a la necesidad de desarrollar la Conjunción a nivel nacional. ${ }^{128}$ Esta Coalición o Conjunción fue atacada duramente por el Obispo de Madrid, Salvador y Barrera y los candidatos finalmente se retiraron. ${ }^{129}$ Se vio en ella el intento de formar un partido político antidinástico, cuestión que influyó decisivamente en la cuestión del traslado del P. Ayala a Ciudad Real, como explico a continuación. Pero la ACN de JP en realidad no compartía una orientación antidinástica, ni siquiera anticonservadora ${ }^{130}$, elementos que continuamente intentó integrar ${ }^{131}$, sino más bien iliberal -como se ha dicho-, y no participó en esta coalición sino indirectamente. ${ }^{132}$ De modo un modo más directo sí que participaría la ACN de P a través de varios de sus prohombres en la fundación de partidos que nacerían de su seno, como el Partido Social Popular, Acción Nacional -rebautizada como Acción Popular- y, posteriormente, la CEDA. Aunque, en efecto, la ACN de JP y El Debate hicieron del tema de la «unión de los católicos» en torno a un "programa mínimo» una de sus reivindicaciones más insistentes, sobre todo a partir de $1913 .{ }^{133}$

128 En El Principado, 22 de agosto 1910, p. 1, se recoge la noticia publicada por El Castellano de Burgos. En este sentido Fernández de Henestrosa pone al corriente de las iniciativas hechas y por hacer desde Madrid, a escala más nacional, concretamente sobre la celebración de una gran manifestación que habría de celebrarse dos meses después, en octubre, y que constituyera un hito semejante a la «manifestación de las mantillas y las peinetas» que, según se afirma, contribuyó a derrocar la anterior república y a restaurar la Monarquía.

129 El P. Ayala lo refiere en sucesivas cartas al nuncio el 21, 22, 23 y 25 de febrero de 1911. Parece que como solución intermedia a la disolución, el Obispo propuso el cambio de nombre de la coalición, cosa que aceptaron independientes de la ACN de JP como Herrera y Roldán, pero a lo que se negaron carlistas e integristas, disolviéndose la Coalición. Cfr. F. Conde: 118 y ss; también en ESF y El Correo español, 21.II.1911 y El Correo español, 24.II.1911. Aunque todavía en 1912 se observan actos de esta coalición y un mitin del propagandista Gómez-Roldán en el que vuelve a insistir en el carácter independiente de la ACN de JP, en la compatibilidad entre antiliberales y dinásticos y en la posibilidad de modificar el nombre de antiliberal de la coalición, El Defensor de Córdoba, 17.VI.1912, p. 1.

130 En su defensa contra las imputaciones del Obispo de Madrid hacia la ACN de JP, el P. Ayala señala: «14. Que el apoyo que se debe dar a los conservadores, cuando hagan algo bueno, es perfectamente compatible, según creo, con que los católicos sean independientes de ellos en su organización», Andrés-Gallego 1993: 297.

131 M. Gómez Roldán envía una carta de invitación a Luis Bahía, del Centro de Defensa Social para su incorporación a la Coalición, pero este deniega la invitación por el tema del término «antiliberal», El Norte (Gerona), 28.II.1911. Por otro lado, en marzo de 1911 el P. Ayala envió a Vico unas «Bases para un congreso católico electoral». Cfr. Robles 1991b: 540. La idea del P. Ayala sugería la posibilidad de integrar circunstancialmente a los conservadores, pero la imposibilidad de unir a los liberales.

132 Para un análisis de la "coalición antiliberal» con referencias a la ACN de JP, véase: Martínez Esteban 2006: 570 y ss.

133 Gutiérrez, ibídem 141 y ss; García Escudero 1983. 
Volviendo a los mítines, después del verano, todas las energías se centraron en la organización y en los mítines preparatorios del gran mitin del 2 de octubre de 1910, como ya se ha indicado. El 18 de septiembre hubo otro gran mitin dirigido a mujeres en Gijón (Casa rectoral de San Pedro) y otro el 19 con más de 2000 asistentes, según la prensa, en el que participaron Herrera, Cuervo y López Vívigo, tomando el protagonismo este último. ${ }^{134}$ El 29 de septiembre, se dio otro mitin preparatorio en los Luises de Madrid, por parte de Herrera, Palanco y Henestrosa, que tenía como tema recurrente la oposición a las escuelas laicas. ${ }^{135}$

Por fin, llegado el gran mitin «monstruo» del 2 de octubre en Madrid se contó en la presidencia con varios de los propagandistas: Bofarull, que asistía también en nombre del presidente del partido carlista; Luis Castel, en nombre de los Luises y Andrés Montalvo, como secretario de la ACN de $\mathrm{JP}^{136}$, quien presentó el acto y las conclusiones. ${ }^{137}$ Hablaron en primer lugar Herrera y Rafael Rotllán, con sendos discursos centrados en la oposición a la política anticlerical de Canalejas. A José M.a Urquijo y al político vasco Esteban Bilbao se les detuvo por orden gubernamental camino de Madrid, prohibiéndoles asistir, pero se leyeron las cuartillas de sus intervenciones. ${ }^{138}$ Asimismo, intervinieron Antonio Marín, en representación de los carlistas y el director del Centro de Defensa Social, Martín Lázaro. Todos los sectores católicos estuvieron nuevamente representados, desde los conservadores, a los integristas, pasando por los independientes y el acto contó con la bendición del Obispo de Madrid, por lo general reacio a las actividades de la ACN de JP. Según informa ESF, la asistencia fue de doce mil a catorce mil en el recinto del frontón, y de dos a tres mil fuera, con lo que señala una cantidad total de dieciséis a dieciocho mil personas. ${ }^{139}$ Asimismo, ESF da noticias del seguimiento y réplica de otros mítines, manifestaciones, "aplechs» y otros actos religiosos de adhesión en diversas ciudades de España:

134 ESF, 21.IX.1910, p. 2; en El Principado, 19.IX.1910, p. 1, se señala que es el primer mitin católico que se celebra en la ciudad. El tema fue la unión de los católicos, en el salón de actos de los jesuitas. En la p. 1, junto a una elogiosa carta del Obispo prior de las órdenes militares al presidente de la Junta de Vizcaya, se da cuenta de mítines preparatorios por toda España: Alicante, Huelva, Guipúzcoa, Granada, Toledo, Córdoba, Palencia, Salamanca, Badajoz, Vitoria, Muniesa, León, Orihuela, Murcia, Alcoy, Villaviciosa. En Galicia, se habla de los actos de la Junta católica de Tuy y de la de Santiago.

135 ESF 30.IX.1910, p. 1 En este también la primera página está dedicada a mostrar la extensión de los mítines preparatorios por toda España, hasta Menorca.

${ }_{136}$ En la presidencia estaba igualmente Igariña, representante de la Juventud Integrista, Conde de Doña Marina, por los tradicionalistas; Rubio Massó, presidente de los Círculos Católicos de Obreros; Yáñez, jefe de redacción de El Debate y representante de la Asociación Integrista.

137 Aquí se observa otra técnica propagandística empleada por los jóvenes propagandistas: utilizaban en su presentación la representación de otras asociaciones para potenciar el efecto de las entidades participantes. Esta misma técnica la reprodujeron cuando intervinieron en junio de 1911 consecutivamente como informantes orales varios de los jóvenes propagandistas ante la Comisión preparatoria de la Ley del Candado, según consta en la documentación del Congreso de los Diputados. Un amplio número de los jóvenes propagandistas fueron juntos -Villa, Roldán, Herrera, etc., y sin embargo se presentaron como miembros de asociaciones diversas: Luises, centro de defensa, etc

138 En ESF se reproduce un telegrama de Urquijo a Herrera en el que se dice que «nos prohíbe la autoridad militar ausentarnos de Bilbao por proceso militar que se nos sigue» ESF 1.X.1910, p. 3.

139 ESF, 3.X. 1909, p. 2.
Pamplona, San Sebastián, Alcoy, Alicante, Barcelona, Valencia, León, Palencia, Calahorra, Burgos, Reinosa, Ciudad Real, Cádiz, Cuenca, Cáceres, Málaga, Sevilla, Huelva, Santander, Gandía, Oviedo, Almería, Verín, Riaño, Jerez, Lérida, Orihuela, etc., y añade un desglose por decenas de pueblos. El total de personas movilizadas aquel día por toda España, según $E S F$, se calculó en seis millones de personas -el total nacional censado en 1910 rondaba los 20 millones-. ${ }^{140}$

Después del mitin monstruo de octubre, habrá que esperar a noviembre para que aparezcan crónicas de nuevos mítines, como el de Rotllán y Chicharro, el 1 de noviembre, en Plasencia. ${ }^{141} \mathrm{~A}$ finales de año, entre el $10 \mathrm{y}$ el $13 \mathrm{de}$ noviembre, podemos destacar la participación de Herrera y Aristizábal en la sesión de clausura de la Asamblea Católica Regional de Galicia en Santiago, en la que Herrera formó parte de la Vicepresidencia de la mesa de Acción Pública ${ }^{142}$ y en la que el discurso de clausura corrió a cargo del Obispo de Burgo de Osma, que celebró la creación de la Liga Católica. ${ }^{143}$ Herrera regresó a Madrid el 16 de diciembre.

La noche del 3 de diciembre de 1910 -día del primer aniversario de la inauguración de la ACN de JP- Gerardo Requejo y Fernández de Henestrosa emprendieron una nueva tanda de mítines por Andalucía y Extremadura, al igual que habían hecho Requejo y Herrera en el diciembre anterior. ${ }^{144}$ No obstante, se trataba de una campaña de mucha menor envergadura por pequeñas localidades de Córdoba y Badajoz. Dentro de esta campaña ocurrió que el mitin previsto para el 8 diciembre en Benalcázar (Córdoba) fue prohibido por el alcalde de este municipio cordobés ${ }^{145}$, pero en El Debate -que aún no tenía relación con la $\mathrm{ACN}$ de JP- se informa de que al día siguiente, como reacción se celebró otro mitin en la muy próxima localidad de Hinojosa del Duque; hábil contraataque que al parecer potenció la asistencia de un gran número de habitantes de Benalcázar en señal de protesta. ${ }^{146}$ El 13 de diciembre, ambos propagandistas dieron otro mitin en La Calzada (Badajoz). ${ }^{147}$ Pero el que obtuvo mayor repercusión de esta tanda fue el de Fuenteovejuna, también contra el anticlericalismo de Canalejas, que tuvo lugar el 16 de diciembre, y al que, según la crónica, asistieron unas dos mil personas, público nada desdeñable para un mitin local. ${ }^{148}$ Pero hay que tener en cuenta que uno de los conferenciantes, Fernández de Henestrosa, tenía una fuerte vinculación con Fuenteovejuna,

140 También se hace un seguimiento de estos mítines y manifestaciones paralelas en La Época, 3.X.1910, pp. 2-3. Indica que Villa y Palanco participaron en uno de ellos en León el mismo 2; en el que un socialista repartió hojas anticatólicas recibiendo "una lluvia de palos», sin que fuera a mayores el incidente.

141 ESF 2.XI.1910, p. 1. En el mitin de Rotllán, de alto contenido social, señala que la acción social debe ser la base de la acción política católica. Alude a la necesidad de formar minorías en torno a candidatos católicos que puedan hacer frente a los partidos liberales en municipios, diputación y las Cortes.

142 El Eco de Santiago, 8.X.19010, pp.1-2.

143 N. González Ruiz e I. Martín, Seglares..., p. 42.

144 ESF 3.XII.1909.

145 ESF 9.XII.1910, p. 2. ED 9.XII.1910. Ambos diarios hicieron una dura crítica frente a las actitudes antidemocráticas de dicho alcalde. Téngase en cuenta que El Debate estaba aún en su primera etapa por lo que no tenía ninguna relación con la ACN de JP.

146 ED 10.XII.1910.

147 ESF 13.XII.1910, p. 3, ED 14.XII.1910.

148 ESF 17.XII.1910, p. 1; ED, 17.XII.1910. 
ya que su padre, Francisco Fernández de Henestrosa y Boza, abogado del Estado y diputado a Cortes en cuatro legislaturas, era natural de esta localidad.

PRINCIPALES REPERCUSIONES DE LA CAMPAÑA DE MÍTINES DE 1909 Y 1910

\section{A) Repercusiones internas: consolidación y crecimiento de la ACN de JP con nuevos miembros y centros}

Al efecto de afianzar el desarrollo inicial de la ACN de JP era fundamental capitalizar los éxitos que se iban obteniendo en los diversos mítines de modo que se tradujeran en nuevos propagandistas y en la subsiguiente creación de nuevos centros locales, como de hecho ocurrió a lo largo de este año.

A partir de la crónica de estos mítines, la prensa nos va aportando información sobre la creación de centros locales de la ACN de JP, con la lógica incorporación de nuevos propagandistas. En este sentido, se informaba del intento de constituir en Gijón la "Asociación de Jóvenes Propagandistas ${ }^{149}$, así como de la constitución de otros centros locales en Vitoria ${ }^{150}$, Granada ${ }^{151}$ y Sevilla. ${ }^{152}$ El centro de Valladolid fue creado seguramente hacia octubre de 1910, pues hay varias cartas de Obispos españoles celebrando la noticia de su creación que les había comunicado su secretario, Rafael Torrecilla, por carta. ${ }^{153}$ Si superponemos estas crónicas periodísticas, podremos recrear el mapa de los primeros Centros de la ACN de JP a lo largo de 1910, para ver cómo coincide llamativamente con los lugares de celebración de estos primeros mítines. Aunque no se conserva el archivo original de la ACN de JP para contrastar estos datos procedentes de las crónicas hemerográficas podemos al menos cruzarlo con el dato de que en febrero de 1911 -con poco más de un año de existencia-, la ACN de JP ya contaba con una cincuentena de propagandistas y con once centros locales. El dato procede de una relación hecha por el P. Valera sj, provincial de los jesuitas, sobre la base de una información que le fue suministrada, sin duda, por el propio P. Ayala. En esta carta, el Provincial jesuita expone que: «De los 50 jóvenes que forman el total de los

149 Reunión que tuvo que aplazarse en varias ocasiones por encontrarse López de Vivigo en Oviedo dando conferencias junto a Herrera, El Principado 27-IX-1910. No se ha encontrado el dato de la fundación por falta ejemplares de fechas posteriores, tan solo de que fue convocada para el 28 y aplazada repetidamente por mítines de Vívigo en diversos lugares de la provincia.

150 Tras informar de una conferencia de Herrera en el Centro de Obreros Católicos, el 18.II.1910, se dice: "Se ha organizado un Centro local de dicha Asociación de Jóvenes propagandistas, preparándose para breve un mitin», ESF, 19 y 21.Il.1910, pp. 2 y 1, respectivamente. También informa La Vanguardia del mitin de Herrera, en el que explicó la misión de la ACN de JP, así como la creación del centro local de Vitoria. La Vanguardia, 19.II.1910, p. 9.

151 En la conferencia de propagandistas de la ACN de JP de Granada se habla del mitin en Loja por parte de los propagandistas granadinos: Antonio Pérez Medina y Leovigildo Ponce de León, no quedando claro si Ramón Collado también era miembro. ESF, 26.II.1910.

152 Según informa El Siglo Futuro: "La Asociación de propagandistas catolices sevillanos celebrará el lunes próximo un mitin monstruo para protestar de la inicua campaña antirreligiosa del gobierno. Hablarán los Sres. Rojas Marcos, Medina, Illanes y Gordillo». ESF 16.VI.1910 p. 2

153 Las cartas son incluidas en el artículo de Andrés-Gallego 1993: 289-290.
Propagandistas de las secciones de Madrid, Sevilla, Huelva, Cádiz, Granada, Badajoz, Valladolid, Vitoria, Bilbao, Murcia y Palencia, sólo hay 3 integristas y 10 carlistas: los 37 restantes son independientes: y entre ellos ninguno es Jefe; sólo hay varios Secretarios». ${ }^{154}$

\section{B) Repercusiones políticas}

El contexto de la carta referida anteriormente fue el incidente que se zanjó con el traslado del P. Ayala a Ciudad Real, bajo petición reiterada del Obispo de Madrid, Salvador y Barrera desde 1910. Tras el fracaso del prelado en su objetivo ante el P. Valera, Provincial toledano de la Compañía, que lejos de trasladarle defendió al P. Ayala, seguramente buscó la mediación última del propio rey Alfonso XIII, que en septiembre de 1911 la solicitó a través del Marqués de Santillana al General de los jesuitas, el P. Wernz. El General escribía al Provincial toledano con fecha 1.XI.1911 ordenando el traslado del P. Ayala. ${ }^{155}$ La solicitud y acusaciones previas del Obispo ante la Compañía -la última en carta de 22.I.1911- se basaban en la supuesta naturaleza política, integrista y antidinástica de la ACN de JP y en la desobediencia de los «jóvenes propagandistas» hacia los Obispos. Que las acusaciones eran infundadas lo demuestra la substanciosa documentación epistolar y documental que José Andrés Gallego dio a conocer en sendos artículos de 1993 y 1995 sobre todo este incidente. Si era, en cambio, más fundada la queja del Obispo de Madrid de que: «El P. Ayala fundó, sin anuencia mía, va ya para dos años una Asociación de jóvenes llamados propagandistas [...]» ${ }^{156}$, aunque como se ha visto, contaba en cambio con la anuencia, jerárquicamente superior, del nuncio Vico, que ofició personalmente el acto litúrgico fundacional, como alegó el provincial toledano en defensa del P. Ayala. ${ }^{157}$ Sin embargo, con el éxito final del Obispo en el confinamiento del P. Ayala en Ciudad Real, lejos «descabezar» a la joven Asociación, lo que se consiguió fue potenciar la figura emergente de un joven Ángel Herrera, quien a partir de entonces asumió la dirección plena de la asociación, aunque el P. Ayala siguiera actuando como mentor y consejero en la distancia. La figura del Obispo de Madrid, Salvador y Barrera, en colaboración con el Marqués de Comillas ${ }^{158}$, aparece en varias ocasiones detrás de toda esta operación contra la ACN de JP pues quizá buscaba que la ACN de JP no hiciera sombra a la Acción Católica oficial y a su órgano

154 José M.a Valera SJ, "Documento sobre el P. Ángel Ayala S. J.», respondiendo a los cargos hechos por el obispo de Madrid. Manuscrito en el Archivium Romanum Societatis lesu, (ARSI) Tolet, leg. 1.003, carp. IV], Citado por Andrés-Gallego 1993: 292.

155 La carta del Marqués de Santillana en nombre del rey fue escrita con fecha 9.IX.1911 y dirigida al Provincial castellano, el P. Bianchi, de clara simpatía alfonsina. El motivo era la supuesta colaboración del P. Ayala en la formación de un partido político antidinástico así como su influencia ante el nuncio en este sentido. Cfr. Andrés-Gallego 1995: 409 y 414.

156 Andrés-Gallego 1993: 287.

157 Ibídem: 293.

158 Andrés-Gallego 1993: 304. J. Andrés-Gallego describe al obispo como: «...hombre posibilista, de talante abierto al liberalismo y amigo del presidente del Gobierno, don José Canalejas...», 1995: 407. También Romanones en sus memorias alude a su «sincera amistad» con el obispo y a sus intentos (infructuosos) por elevarle al episcopado. 
El Universo, en el objetivo de promover una vía para el movimiento católico que fuera más cercana a los principios del catolicismo conservador y dinástico, como se ha dicho anteriormente. Es lo que indica el P. Ayala cuando señala las causas de la oposición e imputaciones del Obispo, entre las cuales destaca: «su deseo, muchas veces manifestado, de que los católicos formen la derecha conservadora» y su convencimiento de que los propagandistas no quieren formarla para «mantenerse con entera independencia y neutralidad en política». Como causas más inmediatas de la oposición, en su defensa el P. Ayala señala el desagrado del Obispo y de los conservadores hacia los propagandistas por su participación el mitin del 2 de octubre-«movimiento que no fue grato a El Universo ni a los conservadores», aunque habían tenido representación en ambos- y en el homenaje a las minorías tradicionalistas que se opusieron a la Ley del Candado. ${ }^{159}$ La subsiguiente oposición entre el nuncio Vico y el Obispo de Madrid también fue manifiesta y tuvo diversos episodios que llegaron hasta Roma. ${ }^{160}$

Por tanto, no cabe duda de la repercusión política que obtuvieron los mítines organizados por la ACN de JP a lo largo del estratégico año de 1910, especialmente los dos «mítines monstruo» en el Jai Alai. Varios hechos lo confirman, además del referido incidente con el Obispo de Madrid y con el rey Alfonso XIII. El primero es la intervención directa del gobierno de Canalejas para intentar impedir el mitin de octubre, deteniendo, por ejemplo, a los miembros organizadores de la Junta de Vizcaya e impidiendo la llegada de sus ponentes. ${ }^{161}$ En segundo lugar, la prohibición del mitin preparatorio de Bilbao, tras una intensa polémica previa que salpicó al propio Canalejas al que desde la prensa católica regional se le acusó repetidamente de sectarismo anticlerical y de ataque a la propia Iglesia y a las libertades de los católicos y que incluso hizo que desde la prensa progresista se le reprochara su actuación. El propio rey revelaba ante el Nuncio la importancia de estos mítines y Romanones lo recogería en sus memorias.

No puede negarse que varias de las actividades promovidas tuvieron un carácter marcadamente antiliberal pero este era un rasgo común a todo el primer catolicismo social español y no específico del integrismo o del tradicionalismo, como ha demostrado Feliciano Montero. ${ }^{162}$ Asimismo, la oposición de la primera ACN de JP al conservadurismo no respondía solamente a motivos político-religiosos, sino también sociales, ya que Herrera, aunque apreciaba a Maura, no veía que los conservadores pudieran implicarse realmente en una acción social orientada a la necesaria redención

159 Andrés-Gallego 1993: 297

160 Robles expone varios casos de acusaciones respectivas de filointegrismo, hacia Vico, y de filoliberalismo y canalejismo, hacia Salvador y Barrera, en su artículo 1991b y señala que el rey Alfonso XIII también medió ante Roma para solicitar el traslado del nuncio, p. 561. Por otro lado, el Obispo de Madrid fue llamado al orden por la Santa Sede por su pastoral de 1911 sobre las normas del Cardenal Aguirre, teniendo que rectificar sus insinuaciones de herejía hacia los católicos tradicionalistas. Cfr. Robles 1991b: 544 y ss.

161 No se logró detener, pero sí se paralizó el «mitin monstruo» organizado con todas las fuerzas católicas en 1913 contra Romanones, tras una nueva intervención del Obispo de Madrid y un escrito de este contra El Debate, publicado en El Correo Español, que fue contestado por uno de los pocos editoriales firmados por Herrera.

162 Cfr. Montero 2007: 106 y ss. del campesinado español pues consideraba que aquel no era "un partido de ideas sino propiamente de 'intereses', basado en el caciquismo, lo mismo que el partido liberal». ${ }^{163}$ No hay que olvidar que Herrera pondría en marcha pocos años después, junto con Antonio Monedero y el P. Nevares, la Confederación Nacional Católico Agraria, así como otras obras sociales de gran calado. Ante esta situación, Herrera consideró necesario crear, al margen del partido conservador y liberal, «un centro de diputados católicos en el Parlamento que vele por los intereses religiosos de la nación». ${ }^{164}$ Así, la ACN de JP aparece apoyando la Coalición Antiliberal o a las minorías tradicionalistas en la oposición a la Ley del Candado, pero siempre suelen aparecer como «católicos independientes». ${ }^{165}$ Por otro lado, desde sus comienzos, la ACN de JP fue asumiendo las consignas pontificias de León XIII y las normas a los católicos españoles de Pío $X$, que derivarían en la posición del "accidentalismo» de las formas de gobierno y en un "posibilismo» hacia el bien común. ${ }^{166}$ La ACN de JP intentó jugar el papel difícil de integrar los distintos elementos de la sociedad y del movimiento católico: desde los elementos conservadores y dinásticos -que en su mayor parte tampoco querían asumir la etiqueta de liberales-, hasta la derecha tradicionalista e integrista. Con ello estaban intentando aplicar los postulados del papado de León XIII en la Cum multa o y las Normas a los católicos españoles de san Pío $X$, al menos en la interpretación del Nuncio, al que no convencían ninguno de los dos extremos: ni el conservador, ni el integrista -pese a las acusaciones del Obispo de Madrid-y que buscaba más bien una «tercera vía»

163 La frase es del propio Maura, al que Herrera parece respetaba y al cual se apoyó años después desde El Debate, Herrera Oria 2002: 383 y ss. En 1918 Maura le ofreció a Herrera y a Antonio Monedero la cartera de agricultura -entonces Dirección General-, ibídem: 484. Pero es muy interesante en este sentido el informe que hizo Herrera hacia 1912 sobre la situación política española, donde afirma: «El partido conservador es enemigo de la acción social porque [...] redime al pueblo, le libra del yugo de prestamistas sin conciencia, comerciantes, explotadores, etc. y como cada labrador u obrero asociado en una obra social es un voto perdido, de aquí que persiga el partido conservador los sindicatos, cajas, cooperativas y demás instituciones populares que destruyen sus nefandos resortes electorales. Dedúcese de lo dicho que es un contrasentido el poner al frente de la acción social a elementos conservadores, porque estos si sirven a las obras sociales traicionan a su partido $y$, si atienden al bien del partido, no pueden ver con cariño las obras sociales». HerreraVico, 6 de abril de 1913, ASV SS 249 (1913) XXII 233-254. El informe lo envió posteriormente Vico al futuro papa Pacelli. Fue recogido por José Luis Gutiérrez en Herrera Oria 2009: 76 y ss.

164 Añade al respecto: «Este centro, ni dinástico, ni antidinástico, será absolutamente independiente de los partidos de turno, pero no enemigo sistemático de ellos, apoyándoles en lo bueno que hagan o propongan según lo preceptuado en las Normas». Se percibe aquí la actitud integradora y proto-posibilista que desarrollará posteriormente Herrera y que se aplicará en partidos como la CEDA. Ibídem.

165 En enero de 1911 figuran varios propagandistas en el homenaje a las minorías tradicionalistas del Congreso que se opusieron a la Ley del Candado. Entre los firmantes, aunque por parte de los Luises, figuran: Manuel Gómez-Roldán, Andrés Montalvo, Ángel Herrera, José M.a Sauras, Santiago Cavengt, Luis Castel, Gerardo Requejo, José Palanco; por parte de los propagandistas, firman: José Manuel de Aristizábal y Mateo de la Villa. ESF, 5.I.1911, p. 1. Por otro lado, Rafael Rotllán fue el que editó y prologó el libro de homenaje a los que se opusieron a la Ley del Candado.

166 Por ello mismo, El Debate apoyó la monarquía sin ser precisamente alfosino y posteriormente acató la II República siendo antirrepublicano. 
independiente y con vocación integradora. ${ }^{167}$ Esta posición intermedia que jugó la ACN de JP le traería, no obstante, serios problemas, tanto del lado tradicionalista/integrista como del pro-dinástico. ${ }^{168}$ De los problemas con los sectores conservadores dan fe los conflictos referidos con el Obispo de Madrid, y las confusiones sobre la ACN de JP como un movimiento integrista e antidinástico, frente a lo cual el P. Ayala llegó hasta a declarar bajo juramento que la acusación era falsa. ${ }^{169}$ Por el lado integrista, se fue produciendo un pronto distanciamiento de los católicos más integristas, como ejemplifica el caso de la baja del miembro fundador Jose M. a Lamamié de Clairac ${ }^{170}$, y también con los órganos e instituciones de esta orientación, como muestra la relación de aversión que en poco tiempo pasó a tener El Siglo Futuro hacia la ACN de $\mathrm{P}$ y hacia El Debate. ${ }^{171}$

167 Una anécdota puede ilustrar el interés de Herrera por la unión entre los católicos. Al parecer, teniendo Herrera tan solo once años escuchó a su padre hablando sobre los enfrentamientos entre católicos y la tristeza por el hecho le llevó a rezar cada día por la unión de los católicos. Refiere la anécdota Sánchez de Muniáin al que se la contó el propio Herrera, fechándola en 1897, Cfr. Sánchez Garrido 2016: 46.

168 Para la posición del P. Ayala y Herrera en la polémica sobre el mal menor y el conservadurismo maurista, véase Robles 1991a: 189. La posición de los jóvenes propagandistas estaba claramente en la línea de los llamados "católicos independientes» y era ajena al maurismo, aunque algunos años después habría una línea maurista en la ACN de $P$ ya que en ella se albergaron diversas sensibilidades políticas, desde tradicionalistas y carlistas, hasta mauristas, posteriormente cedistas y miembros de Renovación Española, e incluso nacionalistas vascos, como José Antonio Aguirre, etc.

169 El P. Ayala declara bajo juramento lo siguiente: "Yo, Ángel Ayala sacerdote de la Compañía de Jesús, puestas las manos sobre el santo Evangelio, juro: 1. Que no soy integrista. 2. Que la Asociación de Jóvenes Propagandistas no es integrista, ni ha hecho jamás campana alguna integrista, ni ha dado motivo para creer que hiciera nunca semejante campaña. 3. Que por el contrario, yo siento de manera opuesta a la de los integristas con lo que toca a muchos de sus procedimientos. 4. Que el espíritu de la Asociación es opuesto al espíritu de los integristas singularmente en lo que toca a muchos de sus procedimientos. 5. Que por eso me miran a mí y a la Asociación los integristas y los carlistas con recelo y desconfianza, como podré demostrar por cartas de los jefes de ambos partidos. 6. Que la Asociación no tiene carácter político determinado sino que se mantiene en un terreno absolutamente independiente.», «Declaración del P. Ayala», en ARSI. Citado por Andrés-Gallego 1993: 296.

170 Es muy significativa en este sentido su salida de la ACN de JP, que nos narra José M. a Gil Robles a propósito de su propia vinculación a la ACN de P: «Llegué a Madrid desde Salamanca bastante prevenido contra ella por algunas amistades de mi familia inspiradas por absurdos criterios integristas, que continuaban frecuentando nuestra casa después de la muerte de mi padre. Procuró influir de manera especial sobre mí la familia presidida nominalmente por don Juan Lamamié de Clairac, cuyo hijo, José María, había sido uno de los ocho «luises» a quienes citó el Padre Ayala en el Colegio de Areneros para proponerles fundar la Asociación. Pero cuando en 1911 Ángel Herrera, otro de los jóvenes fundadores y primer presidente de la misma ocupó la dirección de $E l$ Debate, imprimiéndole un rumbo que los lectores de El Siglo Futuro juzgaron «liberal», los elementos tradicionalistas - por lo menos, José María Lamamié de Clairac-se dieron de baja en la Asociación por considerarse punto menos que traicionados», Gil Robles 1975: 69-70. El contacto de Lamamié con Herrera comenzó cuando ambos eran estudiantes del colegio de San José y posteriormente de la Universidad de Deusto.

171 Sobre el apoyo inicial a la ACN de JP en ESF: «EL SIGLO FUTURO ha asistido con júbilo al nacimiento de la Asociación, ha presenciado y dado noticia de sus trabajos y ofrece sus columnas para cuanto sea darles publicidad y extender por la difusión y propaganda la eficacia de sus trabajos.» ESF, 3.XII.1909. p. 2.
C) Repercusión eclesial: apoyo de la Santa Sede, conexión con la Junta de Vizcaya y gestación del diario El Debate

El propio Herrera vinculó la amplia campaña por el noroeste español al gran mitin de octubre de 1910 y señaló la coordinación que para ello mantuvo con José M.a Urquijo, como líder de la Junta de Vizcaya, convertida en Junta Nacional. Según afirma Herrera: «La Junta de Vizcaya quedó convertida en Junta Nacional, y desde Bilbao se dirigieron todas las operaciones con la rapidez, energía y eficacia que Urquijo ponía en sus empresas. La ACN de P, dirigida entonces por el padre Ángel Ayala SJ, amigo y condiscípulo de Urquijo, fue, en gran parte de España, el brazo ejecutivo de los planes de la Junta de Vizcaya». ${ }^{172}$ A continuación aludía Herrera a su propia gira de mítines por distintas regiones del noroeste español -aunque con un error en el mes de inicio de la misma-:

«Del 18 de agosto al 18 de septiembre recorrí por encargo de Urquijo, toda la zona del noroeste de España: Santander, Asturias, Galicia, el reino de León y Valladolid, para rendir viaje en Bilbao, donde pude comunicar a don José María las más halagüeñas noticias, sin excepción, en todas las provincias recorridas. Aquella gran campaña, que culminó con los actos del 2 de octubre, demostró que era enorme la potencia social de los católicos en España, aunque totalmente falta de organización. Urquijo pensó que era conveniente el dar organización permanente a las Juntas en aquella ocasión constituidas» ${ }^{173}$

Hubo por tanto una estrecha coordinación entre las Juntas, especialmente la Junta Nacional de Vizcaya, liderada por Urquijo, y los propagandistas "que fueron su instrumento» -según reconoce Herrera en su memorias ${ }^{174}$ - a lo que añade la estrategia de acción de las mismas, que desembocaría en el gran mitin del 2 de octubre:

«El plan era el siguiente: las manifestaciones se celebrarían el mismo día, el 2 de octubre de 1910. Debían prepararse durante varios meses por grupos principalmente de propagandistas que recorrerían las capitales constituyendo Juntas y celebrando actos de propaganda [...]. Y se produjo un serio movimiento nacional que alarmó al gobierno. Este prohibió la manifestación de Bilbao. Impidió y prácticamente prohibió la de Navarra. Detuvo a la Junta de Vizcaya, pero no pudo impedir las imponentes congregaciones de hombres en Oviedo, capitales castellanas, levante, y el importantísimo acto de Madrid, celebrado en el frontón Jai-Alai»» ${ }^{175}$

172 En diversas carta de Urquijo en el ASV, señala que la Junta iba a quedar constituida el 7 de julio de 1910. En otro lugar informa de que el éxito en la movilización católica se ha debido al pluralismo católico conseguido: carlistas, dinásticos, independientes, integristas, etc. Asimismo, menciona la existencia de la Junta Católica de Burgos, presidida por Martín Garmendia («dinástico entusiasta») y de la Junta de Orense, por Lorenzo Gil. Cfr. en Conde 2011: 109 y 122, respectivamente.

173 Herrera Oria 2002: 391-392.

174 En su refutación ante las acusaciones de integrismo del Obispo de Madrid, reconoció el P. Ayala: «15. Que mi criterio en éstas cosas es ciertamente el sostenido por la Junta Católica de Vizcaya en sus trabajos de organización, bendecidos por el Sumo Pontífice», Cfr. Andrés-Gallego 1993: 297.

175 Ángel Herrera, s/f: 19-20. También convendría añadir a la estrategia organizativa la creación de una agencia de noticias que canalizaba las noticias locales desde las juntas diocesanas hasta la Junta de Vizcaya, que a su vez la difundía a los periódicos católicos. "Circular a los presidentes de Juntas Católicas» y "Circular a los directores de periódicos católicos». Cfr. Martínez Esteban, Acatar el poder... p. 541. En esta misma obra hay un interesante análisis de la Junta de Vizcaya y de los mítines suspendidos por el Gobierno de Canalejas, v. pp. 519-549. 
Esta intensificación de la colaboración entre los propagandistas de Herrera y Urquijo tendría a su vez otras dos repercusiones importantes para la ACN de JP. Un primer efecto a corto plazo fue el viaje de Herrera y de dos de los colaboradores de Urquijo, Domingo Epalza y Manuel Garmendia, a Roma en 1911 para entrevistarse con el papa San Pío X. Esto supuso un espaldarazo directo del pontífice a la ACN de JP, que se unía al apoyo indirecto a través del Nuncio, auténtico padrino de la asociación. A propósito de este primer viaje a Roma de Ángel Herrera es posible que las Normas pontificias a los católicos españoles de 1911, entregadas al Primado en mayo, pudieran estar parcialmente influidas por esta visita de Herrera ante san Pío X y ante Merry del Val a comienzos de abril de $1911 .{ }^{176}$ En la visita a Roma se cruzaron con la delegación de la posición conservadora, compuesta por miembros cercanos a El Pueblo Vasco, que también visitó al pontífice en esos días. ${ }^{177}$

La segunda consecuencia, relacionada con la anterior, es que un año después, como fruto de esta colaboración, se concretaría el ambicioso proyecto de crear «el gran rotativo católico». Como afirma Herrera a propósito de los orígenes de El Debate: "Surgió la idea de fundarlo en la campaña organizada en 1910 contra la persecución religiosa de Canalejas». Pero esta colaboración fue fruto a su vez del cruce de dos relaciones de amistad previas: la relación previa entre el P. Ayala y Urquijo y la, a su vez, existente entre Herrera con Epalza, cuestión que sería decisiva para el posterior origen de El Debate en noviembre de $1911 .{ }^{178}$ En ambos casos, el punto de conexión fue la Universidad de Deusto, como alma mater de los cuatro y como raíz de la relación. ${ }^{179}$ Pero tampoco sería únicamente la campaña de 1910, ni esta cuádruple relación -Ayala-Urquijo / HerreraEpalza-, el factor desencadenante último en la fundación del histórico diario, ya que el proyecto llevaba en realidad un par de años gestándose por parte del P. Ayala y del nuncio, e incluso con el conocimiento directo de la Santa Sede a través de Merry del Val. Ciertamente, el P. Ayala y el nuncio Vico estuvieron impulsando el proyecto de adquirir un diario existente dándole un enfoque católico suprapartidista al menos desde mediados 1908, como demuestra diversa

176 Sobre la influencia de la visita de Herrera, Andrés-Gallego 1975. Confirma el motivo del viaje a Roma como encargo de Urquijo el propio Herrera, en La Gaceta del Norte, 24.XI.1962. También fue muy intensa la correspondencia e influencia entre el P. Ayala y Vico en 1911 y es plausible su influencia en algunos puntos de las Normas, sobre todo en la 9, según señala Robles 1991b: 540 y ss.

177 Dirigía esta expedición maurista Fernando M.ạ de Ibarra, que escribió una crónica a Maura (28.IV1911) de las entrevistas con los cardenales Merry y Vives y con el papa, señalando la buena impresión recibida de las entrevistas. Cfr. Robles 1991b: 556.

178 Como «excelente amigo» denomina Herrera a Domingo Epalza y López de Lerena. Obras completas, vol. II. BAC, Madrid p. 392. Por otro lado, Herrera confirma el dato del contacto constante entre Ayala y Urquijo para las campaña de la ACN de JP y su conocimiento previo en Deusto, Memorias, A, p. 19.

179 La relación con Urquijo y con Epalza surgió a través de la vinculación de todos ellos con la Universidad de Deusto, pues Urquijo y el P. Ayala, se conocieron en dicha Universidad. Al igual que Herrera y Epalza, que fueron compañeros de la misma promoción de Derecho, y en la presidencia de la Academia de Derecho y Literatura San Luis Gonzaga, en la del Apostolado de la Oración y en la Academia de los Luises de la Universidad de Deusto. Agradezco el trato y la documentación aportada por Dolores Revuelta, directora del Archivo de la Universidad de Deusto en mi visita del 29.IV.2015. documentación existente en el Archivo de los jesuitas de Roma y en el Archivo Secreto Vaticano. ${ }^{180}$ Asimismo, "un grupo de seglares" ya habían enviado las bases del rotativo a la Santa Sede a principios de 1909 , las mismas bases de $E I$ Debate. $^{181}$

\section{CONCLUSIONES}

En sus dos primeros años fundacionales de 1909 y de 1910, la ACN de JP, contando tan solo con un pequeño grupo de jóvenes y desconocidos Luises, logró consolidarse como una asociación de alcance nacional vertebrada en una decena de centros por toda España. Para ello aprovechó la incesante celebración de mítines católicos a través de los cuales se dio a conocer y cosechó a sus primeros miembros fuera de Madrid. Las campañas de 1909 de temática más bien social y de auto-presentación fueron muy importantes en este sentido de vertebración y desarrollo ad intra. En las campañas de 1910 disminuyeron notablemente sus característicos mítines de carácter social, que recuperarían en los años siguientes -para conformar, por ejemplo, la Confederación Nacional Católico Agraria-, centrándose ese año en el anticlericalismo gubernamental. Estas campañas, especialmente las de los dos grandes mítines en el Jai Alai, fueron decisivas a efectos de lograr una enorme repercusión política e hicieron de ella la asociación que estaría llamada a liderar una buena parte del movimiento católico en los años y décadas posteriores. El contacto con José M. a Urquijo y la colaboración de su Junta de Vizcaya en la campaña de 1910 fueron muy importantes para catalizar el efecto y la repercusión nacionales que lograron estas campañas. Por otro lado, Urquijo también fue una figura decisiva en la fundación de El Debate y en el contacto del grupo con la Santa Sede, pero tras la documentación del Archivo Secreto Vaticano recogida en diversos trabajos, no hay duda de que los que iniciaron la fundación del diario, tanto a efectos económicos como de su futura línea editorial -católica independiente y vaticanista-, y los que canalizaron inicialmente el apoyo de Roma, fueron el P. Ayala y el propio

180 Carta de J. M.a García Ocaña, desde ICAI, a I. Zameza, 10.XII.1911, sobre su entrevista con el nuncio en la que este defiende a la ACN de JP y su idea de adquirir un periódico que sirva de órgano de unión entre los católicos, ARSI, Tolet 1003-VII. Leg. 5. Agradezco la ayuda prestada en el ARSI en mi visita el 27.III.2015. En la carta informe del nuncio a Merry del Val de 26.IX.1908, se informa ya del proyecto de adquirir un diario católico por parte de "un padre jesuita», que es sin duda el P. Ángel Ayala porque en otra carta posterior se dice que su hermano, Eduardo Ayala Alarcó, es uno de los promotores económicos. Carta recogida en Conde (ed.) 2011: 103 y 107.

181 Citado por Conde 2011: 107; también se refiere a ella Robles 1997: 227-8. En la carta del 3 de marzo, el nuncio le adjunta las «bases del periódico", redactadas por el P. Ayala, y que según indica habían sido previamente enviadas a Merry del Val por "un grupo de seglares», sin recibir respuesta. Este grupo puede ser la ACN de JP o del entorno del hermano del P. Ayala, a quien contesta el nuncio otra carta sobre el mismo tema. Manuscrito en el Archivium Romanum Societatis lesu, (ARSI) Tolet, leg. 1.003, carp. IV, Citado por Andrés-Gallego 1993: 292. Si la carta en la que iban incluidas estas bases es de 3.III.1909 y se dice que "un grupo de seglares» ya habían enviado con anterioridad unas bases "sustancialmente iguales», habría que retrotraer la redacción de las bases hasta, por lo menos, enero/febrero de 1909. Para un análisis de este periodo pre-fundacional del diario desde marzo de 1909, véase: Martínez Esteban 2006: 452-456. 
nuncio Vico, desde al menos septiembre de 1908, por tanto con anterioridad incluso a la primera constitución de la ACN de JP, en noviembre de ese año.

Por otro lado, los mítines no se organizaron de modo improvisado sino que respondieron a una intensa planificación y a una co-organización con otras fuerzas católicas, primero con la red de los Luises -en 1909- y después a través de instituciones ad hoc, como las Juntas de Defensa católicas, con las que se intentó consolidar y capitalizar sus efectos. Además de la vertebración entre las diversas fuerzas católicas, que se alcanzó hasta un nivel considerable, se aplicaron diversas técnicas propagandísticas para amplificar el efecto de los mítines nacionales, como la celebración de otros mítines preparatorios previos a los mítines centrales -o «monstruo»-, actos de adhesión en paralelo, así como la distribución de la información a través de una agencia de noticias ad hoc y de toda la red de periódicos y revistas católicas afines, tanto a nivel municipal como regional y nacional.

El objetivo de los propagandistas durante estos años iniciales fue el de despertar a la sociedad católica, llevando los principios católico-sociales del magisterio pontificio a la vida pública -en concreto las Normas pontificias de Pío X y los textos católico-sociales de León XIII- e intentar constituir una vía intermedia entre los dos sectores irreconciliables del catolicismo español de la época: los integristas y los conservadores. El decidido apadrinamiento del nuncio Vico fue decisivo en todo ello. Como "católicos independientes» y sin que la oposición al liberalismo de la época derivase en posiciones antidinásticas, ni anticonservadoras, intentaron ser el aglutinante de los dos anteriores. Ante la dificultad de la empresa y ante la pujanza del propio grupo, que buscó una identificación neta con los criterios pontificios -sobre todo con las Normas de 1911-, pronto se erigirían como una tercera fuerza alternativa. Así, en unos años pasarían a llevar la voz cantante de una buena parte del catolicismo social y público español desde la aplicación de los criterios de la unión de los católicos en torno a un programa mínimo, así como desde los principios accidentalistas y posibilistas, tan característicos de esta asociación que, en el decir de J. Andrés-Gallego, estaba llamada a ser «germen de la futura democracia cristiana». ${ }^{182}$ Asimismo, años después parece que Herrera, consternado ante el enfrentamiento de las dos Españas, promovió una incesante labor de acción social que pusiera las bases para una «Tercera España». ${ }^{183}$

\section{BiBLIOGRAFÍA}

Andrés-Gallego, J. 1975. La política religiosa en España, 1889-1913. Madrid: Editora Nacional.

Andrés-Gallego, J. 1993. "Sobre los orígenes de los Propagandistas, ICAI y El Debate». Hispania Sacra 45.

Andrés-Gallego, J. 1995. "La intervención de Alfonso XIII frente Ángel Ayala y los propagandistas». Hispania Sacra 47.

Andrés-Gallego, J. 2009. "La Semana Trágica: los hechos, el impacto y las respuestas». Analecta sacra tarraconensia 82: 227-280.

Ayala, Á. 2002. Obras Completas, IV. Madrid: BAC.
Ayala, Á. 1999. "Formación de selectos», en Obras completas I. Madrid: BAC.

Cárcel Ortí, V. 1988. León XIII y los católicos españoles. Informes vaticanos sobre el estado de la Iglesia en España. Pamplona.

Cárcel Ortí, V. 2003. "Precedentes histórico-jurídicos de la ley «del Candado» documentación diplomática esencial de 1876 a 1910». Analecta sacra tarraconensia 76: 315-492.

Conde, F. Glicerio. (Ed.). 2011. La ACdP, sus hombres y sus obras en el Archivo Secreto Vaticano (1908-1939). Madrid: CEU Eds.

Cueva, J. de la, 1910. Clericales y anticlericales. Santander: Universidad de Cantabria.

Francos Rodríguez, J. 1918. La vida de Canalejas. Madrid.

García Escudero, J. M.a 1983. El pensamiento de El Debate. Madrid: BAC.

Gil Robles, J. M.a 1975. La fe a través de mi vida. Bilbao: Desclée de Brouwer.

Gómez Aparicio, P. 1974. Historia del periodismo español. vol. 3. Madrid: Editora Nacional.

Gutiérrez, J. L. 2010. Historia de la Asociación Católica de Propagandistas. vol. I. Madrid: CEU Ediciones.

Herrera Oria, Á. s/f Memorias del Cardenal Herrera. leg. A. Archivo del Cardenal Herrera: Fundación Pablo VI.

Herrera Oria, Á. 2002. «En el cincuentenario de 'La Gaceta del Norte'» (1951), en Herrera Oria, Obras Completas, vol. II. Madrid: BAC.

Herrera Oria, Á. 2009. Obras completas, vol. IX. Madrid: BAC.

Herrera Oria, Á. 2005. Obras completas, vol. VI. Madrid: BAC.

Martín, I. y González Ruiz, N. 1968. Seglares en la historia del catolicismo español. Madrid: Raycar.

Martínez Esteban, A. 2006, Aceptar el poder constituido. Los católicos españoles y la Santa Sede en la Restauración (1890-1914). Madrid: Facultad de Teología San Dámaso.

Montero, F. 1992. «El movimiento católico en España». Espacio, tiempo y forma V: 343-366.

Montero, F. 2007. «Las derechas y el catolicismo español: Del integrismo al socialcristianismo». Historia y Política 18.

Orella, J. L. 2012. El origen del primer catolicismo social español (Tesis de Derecho Político). Madrid: UNED.

Revuelta, M. 1991. La Compañía de Jesús en la España Contemporánea. (vol. II), Madrid: UNED.

Revuelta, M. 1991. La Compañía de Jesús en la España Contemporánea. (vol. III), Madrid: UPCO.

Robles, C. 1991a. "Jesuitas e Iglesia Vasca (1911-1913)». Príncipe de Viana, año no 52, no 192.

Robles, C. 1991b. "Maura y los católicos». Boletín de la Real Academia de Historia, CLXXXVIII.

Robles, C. 1997. José M. a Urquijo e Ybarra. Opinión, religión y poder. Madrid: CSIC.

Ruiz Sánchez, J. L. 1996. «Los Católicos Sevillanos en la Crisis de la Restauración». Revista de historia contemporánea 7.

Sánchez Arjona, F. 1947. Canalejas. Madrid.

Sánchez Garrido, Pablo. 2016. "Genealogía intelectual de Ángel Herrera (1886-1908). Una revisión desde nuevas fuentes historiográficas». Aportes. Revista de Historia Contemporánea 70.

Sánchez Garrido, P. 2017. «Génesis e identidad del grupo fundacional de la ACN de JP (1904-1909)». Hispania Sacra vol. 69, no 139.

Seoane, M.a C. y Sáiz M. a D. 1996. Historia del Periodismo en España. vol. 3. Madrid: Alianza Editorial.

Sevilla, A. D. 1956. Canalejas. Barcelona: Aedos.

Vázquez de Mella, J. 1911. Discurso notabilísimo sobre la famosa Ley del candado. San Salvador: Arévalo.

Zancada, P. 1911. Canalejas, político y gobernante. Madrid.

\footnotetext{
182 Andrés-Gallego 1995: 406.

183 Para su defensa de la tercera España, véase: Herrera Oria, Ángel. 1963. Obras selectas: 230-1. Madrid: BAC.
} 